VSL-07R5200-1

FINAL REPORT

\title{
RESEARCH PROGRAM TO INVESTIGATE THE FUNDAMENTAL CHEMISTRY OF TECHNETIUM
}

David A. McKeown, Andrew C. Buechele, Wayne W. Lukens, Isabelle S. Muller, David K. Shuh, and Ian L. Pegg

Institution: The Catholic University of America, Vitreous State Laboratory Principal Investigator: Ian L. Pegg

Collaborating Institution: Chemical Sciences Division, Lawrence Berkeley National Laboratory Principal Investigator: David K. Shuh

US Department of Energy

Project Number: EMSP-90163

Grant Number: DE-FG02-04ER63814

Grant Project Officer: John Lee

Project Duration: 10/1/03-9/30/07 
The Catholic University of America Vitreous State Laboratory
Program to Investigate the Fundamental Chemistry of Technetium Final Report, VSL-07R5200-1

\section{Table of Contents}

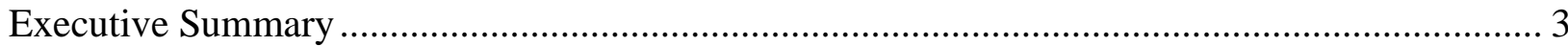

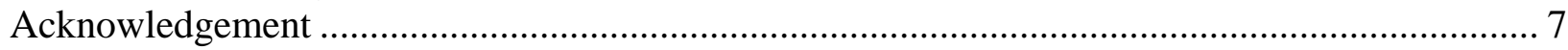

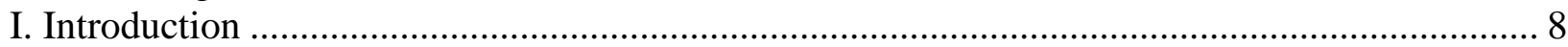

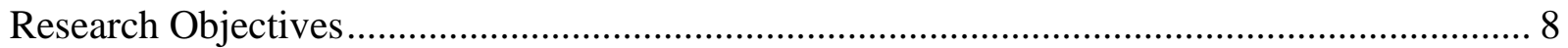

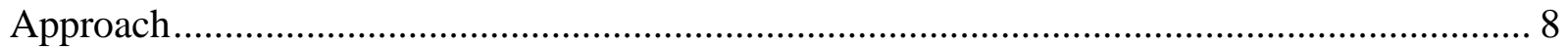

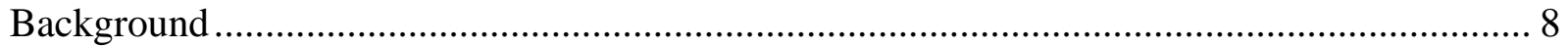

II. Redox Behavior of Technetium and Rhenium in Hanford Low-Activity Waste Glass............ 10

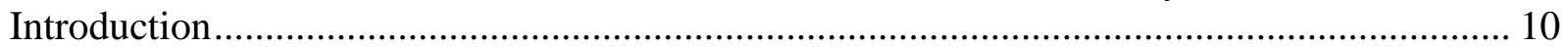

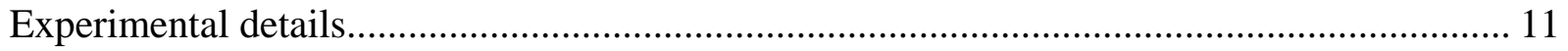

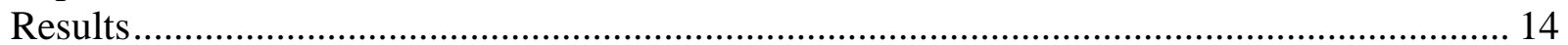

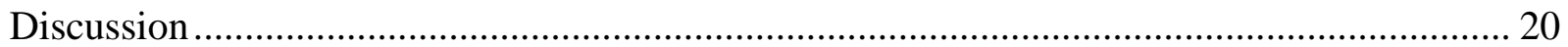

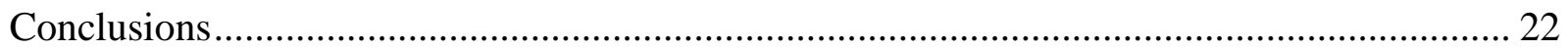

III. Raman Studies of Technetium in Borosilicate Waste Glass.................................................. 24

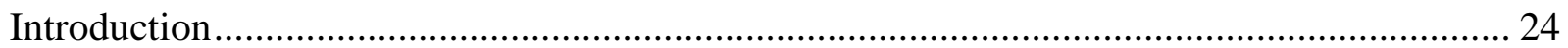

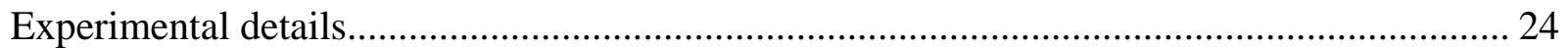

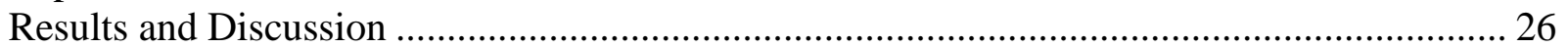

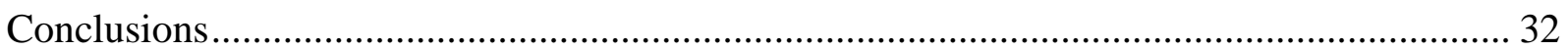

IV. Behavior of technetium and rhenium during borosilicate waste glass vapor hydration tests. 33

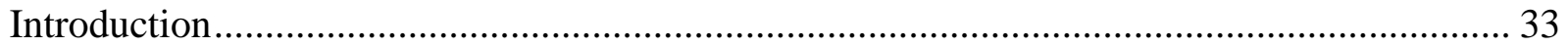

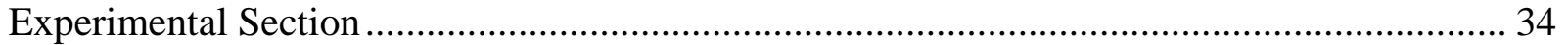

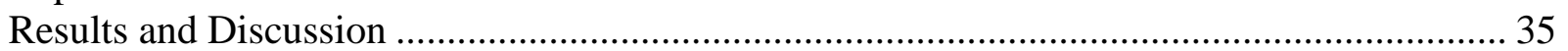

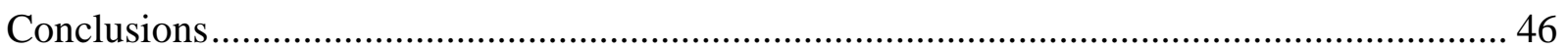

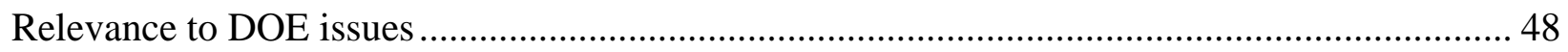

Redox behavior of technetium and rhenium in glass waste forms .......................................... 48

Behavior of rhenium and technetium during the vapor hydration test (VHT) ......................... 48

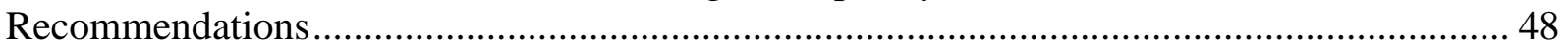

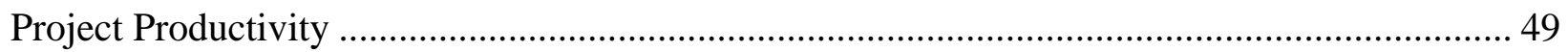

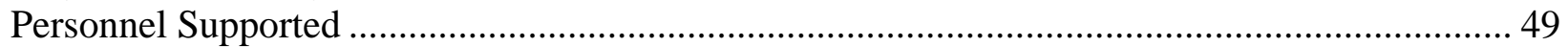

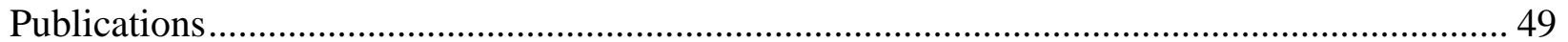

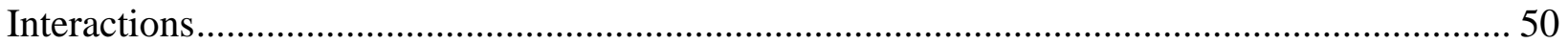

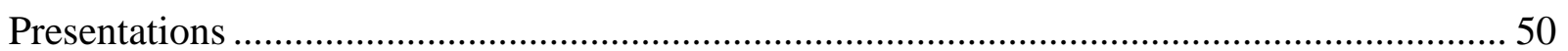

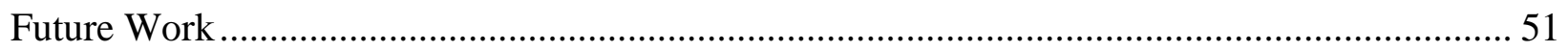

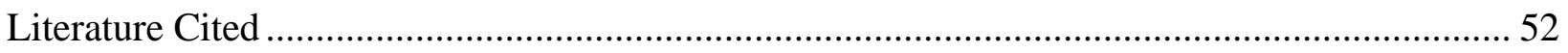




\section{Executive Summary}

The objective of this research is to increase the knowledge of the fundamental technetium chemistry necessary to address challenges to the safe, long-term disposal of high-level nuclear waste posed by this element. The primary issues examined during the course of this project were the behavior of technetium and its surrogate rhenium during waste vitrification and glass corrosion.

Technetium poses a number of challenges to the effective stabilization of nuclear waste in glass waste forms. The main challenge is the volatility of certain technetium compounds at high temperatures that result in decreased technetium loading in the waste and contamination of the melter and off gas systems. Under certain waste vitrification schemes, the volatilized technetium has a large impact on the performance assessment of the repository into which the waste glass will be placed.

A number of studies have shown that reducing conditions decrease the volatility of technetium during vitrification. This observation is consistent with the known chemistry of technetium. Two oxidation states, $\mathrm{Tc}(\mathrm{VII})$ and $\mathrm{Tc}(\mathrm{IV})$, are stable under conditions present during vitrification. A number of $\mathrm{Tc}(\mathrm{VII})$ complexes, including $\mathrm{Tc}_{2} \mathrm{O}_{7}$ and the alkali metal salts of pertechnetate $\left(\mathrm{TcO}_{4}{ }^{-}\right)$, are volatile at glass vitrification temperatures, but no $\mathrm{Tc}(\mathrm{IV})$ compounds are known to be volatile at these temperatures $\left(\mathrm{TcO}_{2}\right.$ can disproportionate to form volatile $\mathrm{Tc}_{2} \mathrm{O}_{7}$ under some conditions). Consequently, oxidizing conditions that promote the formation of $\mathrm{Tc}(\mathrm{VII})$ should increase technetium volatility, while more reducing conditions should decrease technetium volatility, as observed. 
Since the redox behavior of technetium can play a large role in determining its volatility, one goal of this research was to better understand the behavior of technetium in glass as a function of the redox potential of the glass melt. In addition, the behavior of rhenium was examined, since rhenium is commonly used as a surrogate for technetium in waste vitrification studies. A number of glasses similar to Hanford Low Activity Waste (LAW) glasses were prepared under controlled atmospheres. The redox state of the glass was determined from the $\mathrm{Fe}(\mathrm{II}) / \mathrm{Fe}(\mathrm{III})$ ratio in the cooled glass, and the speciation of technetium and rhenium was determined by x-ray absorption fine structure (XAFS) spectroscopy.

Glasses with $\mathrm{Fe}(\mathrm{II}) /$ total iron ratios more than $\sim 0.25$ (equivalent to an oxygen fugacity of 100 ppm) contained either Tc(IV) or metallic Tc (under very reducing conditions). We had hypothesized that rhenium would behave similarly to technetium but would require somewhat more reducing conditions to produce glasses in which $\operatorname{Re}(\mathrm{IV})$ was the predominant species. Surprisingly, we did not find any evidence for $\operatorname{Re}(\mathrm{IV})$ in the waste glasses investigated. Consequently, under certain reducing conditions, rhenium is would not be useful as a surrogate to model the redox behavior of technetium during waste vitrification. However, rhenium is a useful surrogate for technetium under oxidizing conditions where both elements are present in the +7 oxidation state.

The behavior of rhenium and technetium during glass alteration was also examined using the vapor hydration test (VHT). The VHT employs hydrothermal conditions to accelerate the rate of glass alteration. In the VHT, a glass coupon is exposed to a water-saturated atmosphere in a sealed pressure bomb at elevated temperatures for specified time intervals. At the end of the test, 
the coupon is sectioned and analyzed to determine the thickness of the reacted layer, which gives a measure of the rate of reaction, and the types and compositions of the alteration phases produced. Previous work has shown that water diffuses into the glass ahead of the alteration zone and that alteration phases can develop either in place of the native glass or growing out from the coupon surface. However, to the best of our knowledge, Tc behavior is unknown with regard to mobility and speciation within a borosilicate waste form under VHT conditions. In view of the practical importance of rhenium, which is commonly used as a non-radioactive surrogate for Tc, tests were also performed on two Re-containing waste glasses to allow comparisons with the behavior of Tc. The speciation and local coordination environments of Tc and Re, in the original glasses and the corresponding VHT samples, were determined using XAFS spectroscopy.

The XAFS and scanning electron microcopy (SEM) information obtained for the original Tc-containing glasses and corresponding VHT samples shows that the alteration processes that took place, significantly changed the Tc valence and distribution within each sample. XAFS data show that despite having different initial Tc distributions in the two original waste glasses, all Tc was reduced to Tc(IV) as both glasses were altered under VHT conditions; this behavior is likely due to scavenging of oxygen due to corrosion of the stainless steel vessel. Both XAFS and SEM show that Tc concentrated near the VHT sample surface. Since there is no clear evidence from SEM or X-ray diffraction of Tc-containing crystals in either VHT altered sample, amorphous Tc-silicate gel-like phases may have formed near the sample surface.

Re behaved quite differently from Tc in response to VHT alteration. Re speciation remained unchanged from the original glass to the altered samples, where most, if not all Re is present in 
the +7 oxidation state as perrhenate $\left(\mathrm{ReO}_{4}^{-}\right) . \mathrm{Re}_{2} \mathrm{O}_{7}$ concentrations increase from small values near the VHT sample surface to values near that for the original glass toward the sample center. This behavior indicates that some Re was lost from the outer portions of the VHT coupon, which is not consistent with Tc behavior. Re is not a good surrogate for Tc under VHT conditions, which reinforces the earlier findings concerning different Tc and Re behavior as these elements are incorporated into waste glasses. 


\section{Acknowledgements}

This work was supported by the Environmental Management Science Program, Office of Biological and Environmental Research, Office of Basic Energy Sciences. In addition to the work performed at The Catholic University of America, portions of this research was performed at the Lawrence Berkeley National Laboratory, which is operated by the U. S. DOE under Contract No. DE-AC02-05CH11231 and at the Stanford Synchrotron Radiation Laboratory, a national user facility operated by Stanford University on behalf of the U.S. Department of Energy, Office of Basic Energy Sciences. 


\section{Introduction}

\section{Research Objectives}

The primary objective of this work is to better understand the fundamental chemistry of technetium throughout its waste cycle, from its behavior in high level waste tanks and waste form materials to its behavior in waste repositories and closed high level waste tanks. The long-term immobilization of technetium is complicated by uncertainties about its behavior in waste form materials. For example, previous work has shown that technetium will not remain reduced in grout containing blast furnace slag due to oxidation of lower valent technetium species by atmospheric oxygen; consequently, technetium leach rates from reducing grout waste forms should be expected to increase as the grouts age and oxidize. ${ }^{1}$ Our proposed research complements previous studies in two ways. The speciation, leaching, and volatilization of technetium in the other major U.S. waste form, glass, has been studied to determine the role of technetium oxidation state in its behavior. Analogous information has been obtained for rhenium in the same glasses, so that large-scale experiments using rhenium as a technetium surrogate can more accurately predict the behavior of technetium.

\section{Approach}

An integrated approach was used to address the main research objectives, the redox behavior of technetium and its surrogate rhenium in waste glasses and the behavior of technetium and rhenium in glasses during corrosion. The first focus is the redox behavior of technetium and rhenium during the vitrification of waste glasses analogous to Hanford Low Activity Waste (LAW) glasses. Glasses were prepared using Hanford waste surrogates and the same glass precursors as the actual waste glasses with added technetium and rhenium. The glasses were prepared under a variety of redox potentials by varying the composition of the atmosphere above the melt (the actual redox of each glass was determined from the $\mathrm{Fe}(\mathrm{II}) / \mathrm{Fe}$ (total) ratio of each glass). The speciation of technetium and rhenium were determined using $\mathrm{x}$-ray absorption fine structure (XAFS) and Raman spectroscopy. The redox potential of the Tc(VII)/Tc(IV) couple was determined from the ratio of Tc(VII) to Tc(IV) in the glasses as a function of the glass redox potential determined from the $\mathrm{Fe}(\mathrm{II}) / \mathrm{Fe}$ (total) ratio. Rhenium behaved very differently from technetium under these conditions and was found to be a poor surrogate for technetium.

The behavior of technetium and rhenium during glass corrosion was probed using the vapor hydration test (VHT). VHT results in the rapid alteration of the glass into more stable crystalline products. The altered sample was studied by a combination of optical microscopy, scanning electron microscopy (SEM), and x-ray absorption fine structure (XAFS) spectroscopy.

\section{Background}

The radioactive chemical wastes from the nuclear weapons production program are a significant and costly legacy of the cold war. These wastes, the bulk of which are currently stored in large underground tanks at the Hanford and Savannah River Sites, will be immobilized in grout or glass and entombed in waste repositories either on site, in the case of LAW, or in a National Waste Repository for $\mathrm{HLW}^{2}$ One of the radionuclides of greatest concern in these repositories is ${ }^{99}$ Tc because environmentally mobile pertechnetate makes ${ }^{99}$ Tc one of the major contributors to 
off site contamination via ground water. ${ }^{3}$ Consequently, the behavior of technetium often drives the selection and formulation of waste forms.

According to current plans, technetium will be immobilized in two very different waste forms, glass and grout. Glass will be used to immobilize both the high level waste (HLW) and the low activity waste (LAW) streams at Hanford. Glass is currently used to immobilize the high activity waste stream at Savannah River, but this waste stream contains very little technetium. ${ }^{4}$ Grout is currently used to immobilize the low activity waste stream at Savannah River, which contains the vast majority of technetium. Grout also will be used to fill the empty high level waste tanks at both sites to reduce the migration of radionuclides from the tank "heels", which is the waste that cannot physically be removed from the tanks. Grout and glass waste forms present different challenges and uncertainties with respect to technetium immobilization.

In glass, the preferred waste form for HLW, technetium presents two problems: the loss of volatile technetium species during vitrification and leaching of technetium from the glass. The chemistry of technetium involved in these processes is not well understood. A large portion of the technetium can be lost during vitrification due to the volatility of certain Tc(VII) species, which have not been completely identified. ${ }^{5}$ Creating more reducing conditions in the glass melt can decrease the amount of technetium lost, but excessively reducing conditions can lead to processing problems (e.g., through he formation of molten metal and sulfide phases) and, ultimately, damage to joule-heated ceramic melters. The second factor that complicates long-term disposal of technetium in glass is a lack of information about the speciation of technetium in glasses. It is not known whether the nature of the technetium species plays a role in its leach rate or if the leach rate is entirely determined by the durability of the glass matrix. Furthermore, little is known about the incorporation of technetium species into glass alteration phases. 


\section{Redox Behavior of Technetium and Rhenium in Hanford Low-Activity Waste Glass}

\section{Introduction}

The production of plutonium in the U.S. during the Cold War has generated approximately 80 million gallons of high-level nuclear waste, which is currently stored in large underground tanks at the Savannah River site in South Carolina and at the Hanford site in eastern Washington. ${ }^{2}$ Treatment and safe disposal of this waste is among the most challenging remediation projects in the U. S. The current plan for stabilization of this waste includes separation into a high-activity and a low-activity waste stream. ${ }^{2}$ The high-activity waste stream, which contains the bulk of the radioactivity but only a small volume of the waste, will be converted into glass (vitrified) and sent to the high-level waste repository, currently planned at Yucca Mountain. The low-activity waste stream contains most of the chemical constituents of the waste including large amounts sodium nitrate, sodium nitrite, sodium hydroxide, and small amounts of organic compounds such as EDTA, formate, and acetate. The low-activity waste stream will also contain the majority of the ${ }^{99}$ Tc present in the waste tanks at the Savannah River and Hanford sites. At the Savannah River site, the low-activity waste stream is currently stabilized in grout waste form, Saltstone, while at the Hanford Site, the low-activity waste stream will be vitrified. ${ }^{2}$ In both cases, the resulting low-level waste form will be interred in an on-site repository.

The radionuclides ${ }^{237} \mathrm{~Np},{ }^{127} \mathrm{I}$, and ${ }^{99} \mathrm{Tc}$ are of particular concern in the high-level waste repository due to their long half-lives and high environmental mobility. ${ }^{6}$ In the low-activity waste repositories at the Savannah River and Hanford sites, ${ }^{99} \mathrm{Tc}$ is generally the radionuclide of greatest concern since it dominates the dose received by people living off-site who drink groundwater or use it for agriculture. ${ }^{3,7,8}$ The main reasons that ${ }^{99} \mathrm{Tc}$ is so important in determining the off site dose are its high fission yield ( $6 \%)$, which results in a large inventory of ${ }^{99} \mathrm{Tc}$ in high-level nuclear waste, its long half-life, 213,000 yr, and the high solubility and environmental mobility of pertechnetate, $\mathrm{TcO}_{4}{ }^{-}$, the most stable form of $\mathrm{Tc}$ in aerobic environments.

In addition to creating challenges for the long-term disposal of nuclear waste, technetium also creates significant problems for vitrification of nuclear waste due to its volatility under these conditions. 5-12 During vitrification, the volatile technetium compounds that are lost from the glass melt must be captured in the off-gas treatment equipment. Secondary wastes from the off-gas treatment systems must then be either recycled or stabilized in alternative waste forms, which increases the amount of waste created. Under the conditions present in the glass melt, only $\mathrm{Tc}(\mathrm{VII})$ and $\mathrm{Tc}(\mathrm{IV})$ are expected to be present since $\mathrm{Tc}(\mathrm{V})$ and $\mathrm{Tc}(\mathrm{VI})$ are unstable with respect to disproportionation under these conditions. A number of Tc(VII) compounds have significant volatility at the temperatures (typically $1100-1200{ }^{\circ} \mathrm{C}$ ) at which waste is vitrified. ${ }^{5,11,12}$ On the other hand, lower valent Tc compounds are less volatile under these conditions since reducing conditions reduce the amount of Tc lost during vitrification. ${ }^{5,13,14}$ Consequently, one of the major factors in controlling Tc volatility during vitrification is the redox state of the melt. Since iron is the most abundant redox-active element in the glass, the redox state is generally expressed as the ratio of iron that is present as Fe(II) to the total amount of iron, Fe(II)/ $/ \mathrm{Fe}$. Most nuclear waste vitrification processes operate under relatively oxidizing conditions, typically $\mathrm{Fe}(\mathrm{II}) / \Sigma \mathrm{Fe}<$ 
0.3 , to prevent the formation of separate metallic and metal sulfide phases, ${ }^{15}$ which can compromise the operation of the glass melter.

In addition to presenting problems for the vitrification of waste, Tc volatility also creates practical challenges for the development of waste-glass formulations. While the preparation of Tc-bearing glasses on the small, crucible scale is relatively straightforward, preparation of Tc-bearing glasses at larger scales is much more difficult due to the problems caused by Tc contamination of the melter and associated equipment, especially the effluent gas treatment system. For this reason, Re is often used as a non-radioactive surrogate for Tc in such large-scale experiments. ${ }^{5,11}$ In analogy to Tc chemistry, Re(VII) and Re(IV) are assumed to be stable in the glass melt. Although $\mathrm{ReO}_{3}$ is known, it is unstable towards disproportionation above $300{ }^{\circ} \mathrm{C}$. ${ }^{16}$ However, Re is substantially different from Tc in one respect: the standard reduction potentials, in water, for the reduction of $\mathrm{TcO}_{4}{ }^{-}$and $\mathrm{ReO}_{4}{ }^{-}$to $\mathrm{Tc}$ (IV) and $\mathrm{Re}(\mathrm{IV})$ are significantly different, 0.74 and $0.51 \mathrm{~V}$, respectively. ${ }^{17,18}$ This difference is of great practical importance when using $\mathrm{Re}$ as a surrogate for Tc in the development of conditions used to vitrify waste.

Since $\mathrm{Tc}(\mathrm{IV})$ is less volatile than $\mathrm{Tc}(\mathrm{VII})$, reducing conditions decrease technetium volatility. Because of the difference in reduction potentials for $\mathrm{TcO}_{4}{ }^{-}$and $\mathrm{ReO}_{4}{ }^{-}$, a substantially more reducing redox environment would be required to reduce $\mathrm{ReO}_{4}{ }^{-}$in comparison to $\mathrm{TcO}_{4}{ }^{-}$. To investigate the effect of Tc redox state on Tc volatility, as well as the behavior of Re as its surrogate under the conditions present during vitrification, it is necessary to know the redox conditions that are required to produce $\mathrm{Tc}(\mathrm{IV})$ or $\mathrm{Re}(\mathrm{IV})$ in nuclear waste glass. The redox behavior of $\mathrm{Tc}$ and $\mathrm{Re}$ in a borosilicate melt has been studied previously by square-wave voltammetry, and quite different results were obtained for Tc and Re. ${ }^{19}$

The goal of the present study is to better understand the effect of redox environment on Tc and Re during vitrification. Toward that end, a series of glass samples was prepared under a range of redox conditions. Among these glasses are examples that contain only Re, only Tc, and both Tc and Re, the latter of which allows the direct comparison of the behavior of the two elements under identical redox conditions. The formulations of these glasses is similar to those that will be used to stabilize the low-activity waste stream at the Hanford site. ${ }^{3}$ The glasses reported here were prepared from the same solid glass formers as planned for the Hanford facility $\left(\mathrm{SiO}_{2}\right.$, $\mathrm{B}(\mathrm{OH})_{3}, \mathrm{Fe}_{2} \mathrm{O}_{3}$, etc.) together with a chemical simulant of the anticipated low-activity waste stream to which Tc and/or Re was added as $\mathrm{TcO}_{4}{ }^{-}$or $\mathrm{ReO}_{4}{ }^{-}$.

The speciation of Tc and Re was determined using X-ray absorption fine structure (XAFS) spectroscopy. In glasses where either element was present as a single species, extended x-ray absorption fine structure (EXAFS) was used to determine the local structure of the metal ion and to identify the species. The X-ray absorption near edge structure (XANES) spectra of these species were used as standards to determine the speciation in glasses that contained a mixture of species.

\section{Experimental details}

Reagent-grade chemical stock compounds were used for glass synthesis. Water was deionized using a MilliQ system. Oxide components of the prepared glasses were determined by X-ray fluorescence (XRF) spectroscopy with a relative uncertainty of $4 \%$. XRF analyses utilized an 
ARL 9400 X-ray fluorescence spectrometer with XRF composition values determined using NIST standard glasses as standards. Technetium concentrations were determined by liquid scintillation measurements on acid-dissolved glass samples and have an uncertainty of $4 \% . \mathrm{B}_{2} \mathrm{O}_{3}$ and $\mathrm{Li}_{2} \mathrm{O}$ values were determined by direct-coupled plasma atomic emission spectroscopy on acid-dissolved glass samples. The purity of all crystalline standards used in this study was verified by powder X-ray diffraction. $\mathrm{Fe}(\mathrm{II}) / \mathrm{Fe}$ (total) ratios were determined colorimetrically using a manual adaptation of the method described by Whitehead and Malik, and have an absolute uncertainty of $0.4 \% .^{20,21}$

Two groups of borosilicate glasses were investigated. The first group, crucible glasses, was prepared in a vertical tube furnace by suspending a Pt / 4\% Au crucible in the center of the tube. The top of the tube was externally cooled and contained quartz wool to trap the volatilized Tc species. Prior to heating, the furnace was purged with gas $\left(60 \mathrm{~mL} \mathrm{~min}^{-1}\right.$ for 2 hours, total volume of the furnace is $360 \mathrm{~mL}$ ) through a long needle. During the glass synthesis, gas was slowly passed over the top of the tube and through a set of bubblers to trap any escaping Tc. These glasses were formulations developed for the low-activity waste Envelope C (LAWC) (specifically, for tank AN-107) and Envelope A (LAWA) (specifically, for tanks AP-101 or AN-105) at the Hanford Site. ${ }^{22}$ The glasses were prepared by spiking a tank waste simulant (1.55 mL for LAWC glasses, and $1.60 \mathrm{~mL}$ for LAWA glasses) with $\mathrm{NaTcO}_{4}(0.32 \mathrm{~mL}, 0.106 \mathrm{M}$, $34 \mu$ moles) and $\mathrm{NH}_{4} \mathrm{ReO}_{4}(0.54 \mathrm{~mL}, 0.20 \mathrm{M}, 0.11 \mathrm{mmol})$, stirring to create a homogeneous mixture and then adding the glass components (1.63 $\mathrm{g}$ for LAWC glasses and $1.93 \mathrm{~g}$ for LAWA glasses) to form a slurry, which was then heated according to the following schedule:

$$
\begin{aligned}
& 30{ }^{\circ} \mathrm{C} \stackrel{10 \mathrm{~min}}{\longrightarrow} 110^{\circ} \mathrm{C} \stackrel{2 \mathrm{hr}}{\longrightarrow} 140{ }^{\circ} \mathrm{C} \stackrel{3 \mathrm{hr}}{\longrightarrow} 700^{\circ} \mathrm{C} \\
& 700{ }^{\circ} \mathrm{C} \stackrel{2 \mathrm{hr}}{\longrightarrow} 770{ }^{\circ} \mathrm{C} \stackrel{2 \mathrm{hr}}{\longrightarrow} 1150{ }^{\circ} \mathrm{C} \stackrel{4 \mathrm{hr}}{\longrightarrow} 1150^{\circ} \mathrm{C}
\end{aligned}
$$

The glass was cooled to room temperature in the furnace then removed from the crucible. The compositions of the examples of LAWA and LAWC glasses are given in Table 1, and the synthesis conditions are given in Table 2. The compositions of the glass components and the waste simulants are given in the supplementary material.

Table 1. Compositions (wt. \%) determined by XRF of crucible glasses ${ }^{\mathrm{a}}$

(all glasses prepared in air)

\begin{tabular}{lllllllllllllll} 
Sample & Glass Type & $\mathrm{TcO}_{2}$ & $\mathrm{ReO}_{2}$ & $\mathrm{SiO}_{2}$ & $\mathrm{Fe}_{2} \mathrm{O}_{3}$ & $\mathrm{Al}_{2} \mathrm{O}_{3}$ & $\mathrm{~B}_{2} \mathrm{O}_{3}$ & $\mathrm{Li}_{2} \mathrm{O}$ & $\mathrm{Na}_{2} \mathrm{~K}_{2} \mathrm{O}$ & $\mathrm{MgO}$ & $\mathrm{CaO}$ & Other $^{\mathrm{C}}$ \\
\hline $\mathrm{II}-118$ & LAWA & 0.005 & $--{ }^{\mathrm{b}}$ & 44 & 7.5 & 5.9 & 9.1 & 0.23 & 16.0 & 2.7 & 2.1 & 2.1 & 8.4 \\
$\mathrm{II}-121$ & LAWC & 0.003 & $--{ }^{\mathrm{b}}$ & 46 & 5.9 & 6.2 & 10.7 & 2.4 & 12.4 & 0.36 & 1.7 & 4.9 & 7.9 \\
$\mathrm{II}-127$ & LAWC & 0.048 & 0.04 & 45 & 5.9 & 6.2 & 10.3 & 2.2 & 15.6 & 0.38 & 1.6 & 4.7 & 7.6 \\
$\mathrm{II}-128$ & LAWC & 0.057 & 0.04 & 47 & 6.6 & 6.5 & 9.9 & 2.2 & 16.1 & 0.25 & 1.6 & 5.1 & 7.6 \\
$\mathrm{II}-129$ & LAWA & 0.02 & 0.01 & 40 & 6.6 & 5.9 & 8.7 & $--{ }^{\mathrm{b}}$ & 19.5 & 4.1 & 1.9 & 1.9 & 7.2 \\
\hline
\end{tabular}

a) Relative uncertainty of $6 \%$ for the analyses on this sample

b) Element not present or below detection limit.

c) The other principal components are $\mathrm{TiO}_{2}, \mathrm{ZrO}_{2}$, and $\mathrm{ZnO}$ 
Table 2. Samples prepared under different redox conditions

\begin{tabular}{cccc}
\hline Sample Name & Glass Type & Atmosphere & Appearance \\
\hline II-206 & LAWA & Air & Brown \\
II-205 & LAWC & Air & Brown \\
II-210 & LAWA & $\mathrm{N}_{2}$ & Dark brown \\
II-212 & LAWC & $\mathrm{N}_{2}$ & Dark green \\
II-214 & LAWA & $1: 1 \mathrm{CO}_{2} / \mathrm{CO}$ & Dark green w/metallic film \\
II-216 & LAWC & $1: 1 \mathrm{CO}_{2} / \mathrm{CO}$ & Dark green w/ metallic film \\
II-218 & LAWC & $100 \mathrm{ppm}_{2}$ in $\mathrm{N}_{2}$ & Dark green \\
II-219 & LAWA & $100 \mathrm{ppm}_{2}$ in $\mathrm{N}_{2}$ & Green-brown \\
\hline
\end{tabular}

The second group, melter glasses (Table 3), contains two sets of glasses. One set (LAWA1) was synthesized under oxidizing conditions and used a LAW Sub-Envelope A1 waste simulant. ${ }^{23}$ The other glass set (HLWAZ-102) was synthesized under more reducing conditions and used a HLW AZ-102 waste simulant. ${ }^{23}$ Rhenium-bearing waste glasses were synthesized in two similar continuously-fed DuraMelter 100 (DM100) ceramic-lined, Joule-heated melters, where the melt pools ( $110 \mathrm{~kg}$ for LAW and $\sim 180 \mathrm{~kg}$ for HLW) were maintained at $1150{ }^{\circ} \mathrm{C}$ and agitated using an air bubbler. Glass production rates of up to $220 \mathrm{~kg}$ glass per day were used for each production run of about 100-hours in duration. Glass samples from the melter were extracted at various times during the melter run as Re concentrations were changed in the melt pool.

Table 3. Composition (wt. \%) determined by XRF of rhenium glasses prepared in a continuous melter

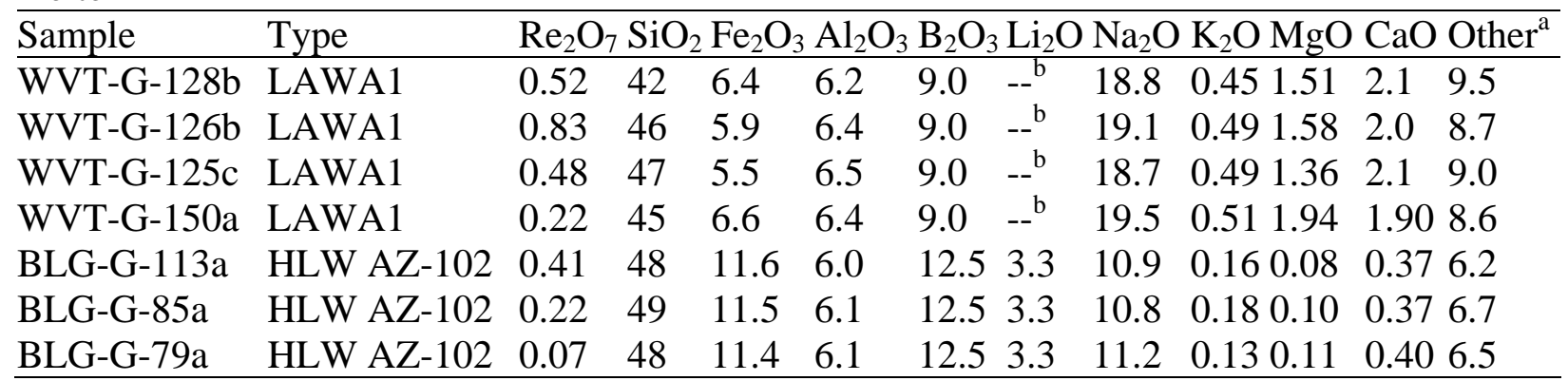

a) The other principal components are $\mathrm{TiO}_{2}, \mathrm{ZrO}_{2}$, and $\mathrm{ZnO}$

b) Element not present or below detection limit

Tc K-edge (21044 eV) and Re $\mathrm{L}_{2}$-edge (11959 eV) XAFS data were collected at the Stanford Synchrotron Radiation Laboratory beamlines 4-1 and 11-2 using a Si (220) double crystal monochromator. The harmonic content of the beam was reduced with a harmonic rejection mirror or by detuning the monochromator by $50 \%$. Samples were mounted in polycarbonate holders sealed with Kapton tape. The holders were doubly contained in heat sealed polyethylene pouches. Data were recorded in transmission using Ar-filled ion-chambers or in fluorescence using a four-element Ge detector and was corrected for detector dead time effects. For crucible glasses, the top surface of the intact glass ingot, which was in contact with the tube furnace atmosphere, was probed with the exception of sample II-219, which shattered. The top surfaces 
of the glass pieces were examined in this case. The information depth, above which $68 \%$ of the observed fluorescence photons originate, is $0.26 \mathrm{~mm}$ at the Tc K-edge and $0.06 \mathrm{~mm}$ at the $\mathrm{Re} \mathrm{L}_{2}$ edge. $^{24}$

EXAFS data analysis was performed by standard procedures ${ }^{25}$ using the programs ifeffit, ${ }^{26}$ and Athena/Artemis; ${ }^{27}$ theoretical EXAFS phases and amplitudes were calculated using FEFF7. ${ }^{28}$ EXAFS data analysis and XANES fitting were performed as previously described. ${ }^{1,29}$ The XANES fitting errors are extremely sensitive to the slope of the spectrum produced by the pre-edge correction; to minimize the errors, the slope of the XANES spectra was included in the fit. The Tc and Re XANES spectra were also analyzed by principal component analysis using the program SixPack. $^{30}$ The Tc spectra were spanned by 3 eigenvectors, which produced good fits for the spectra of $\mathrm{TcO}_{4}{ }^{-}, \mathrm{Tc}(\mathrm{IV})$, and $\mathrm{Tc}(0)$ in glass. The Re spectra were spanned by 2 eigenvectors, which produced good fits for the spectra of $\mathrm{ReO}_{4}{ }^{-}$and $\mathrm{Re}(0)$ in glass.

The Tc XANES data for the glass samples had higher resolution than the reference spectra, so the spectra of the glasses were convolved with a $1 \mathrm{eV}$ wide Gaussian. In addition, Tc K-edge XANES spectra for glasses II-205 through II-219 were smoothed using three iterations of simple three-point smoothing. The Tc K-edge experimental resolution was $\sim 3 \mathrm{eV}$ and the Tc K-edge core-hole broadening is $\sim 6 \mathrm{eV}$ (from FEFF7) yielding a spectral resolution of $\sim 7 \mathrm{eV}$; the fit had a range of $150 \mathrm{eV}$ (21 independent data points) and used six parameters (energy shift, y-axis shift, $\mathrm{y}$-axis slope, and contribution of three standards). The fit for sample II-219 had a range of 120 $\mathrm{eV}$ due to noise in the pre-edge region. The Re $\mathrm{L}_{2}$-edge XANES experimental resolution was $\sim 2 \mathrm{eV}$ and the Re $\mathrm{L}_{2}$ edge core-hole broadening is $\sim 5 \mathrm{eV}$ yielding a spectral resolution of $\sim 6 \mathrm{eV}$; the fit had a range of $120 \mathrm{eV}$ (20 independent data points) and used seven parameters (as above, but four standards). The fitting process was done in two stages. First, the XANES spectra were fit including all of the reference spectra. Whenever the contribution of the reference spectrum was within one standard deviation of zero, the spectra were fit again with that spectrum excluded. The final fit therefore includes only reference spectra that have non-zero contributions to the fit. The results of initial fitting are included in the supplementary material.

\section{Results}

Identities of the technetium and rhenium species present in glass. One spectroscopic technique that has been very useful for determining the speciation of Tc in samples that contain a mixture of species is fitting the Tc K-edge XANES spectra of samples using the XANES spectra of known Tc compounds as standards. ${ }^{1,} 29$ To determine the speciation of Tc and Re in glass samples in this manner, it is necessary to obtain standard spectra corresponding to the specific species present in the glass. This can be accomplished by using pure compounds, such as $\mathrm{ReO}_{2}$, or by demonstrating that the reference sample contains only a single species. The reference spectra for Tc(VII) and Tc(IV) in glass were previously obtained, ${ }^{29}$ but the reference spectra for metallic Tc in glass and for the Re species have not been reported. In this study, $\mathrm{ReO}_{2}$ and $\mathrm{ReO}_{3}$ were used to obtain the reference spectra for $\mathrm{Re}(\mathrm{IV})$ and $\mathrm{Re}(\mathrm{VI})$. The other standard spectra were from glass samples that contained a single species as determined by EXAFS.

$\mathrm{NH}_{4} \mathrm{ReO}_{4}$ was initially used as the $\mathrm{Re}(\mathrm{VII})$ standard, but its $\mathrm{Re} \mathrm{L}_{2}$ XANES spectrum is somewhat different from that of $\mathrm{Re}(\mathrm{VII})$ in glass in that the large peak at the absorption edge (white line) of $\mathrm{Re}(\mathrm{VII})$ in glass is broader than that of $\mathrm{NH}_{4} \mathrm{ReO}_{4}$. The EXAFS spectra of $\mathrm{Re}(\mathrm{VII})$ 
in glasses prepared in both crucibles and melters are shown in Figure 1, and the fit parameters are given in Table 4. In all of these cases, the only important Re species in the glass is Re(VII), and the fitting parameters are similar. The XANES spectrum of II-205 was used as the standard for $\operatorname{Re}(\mathrm{VII})$ in glass.
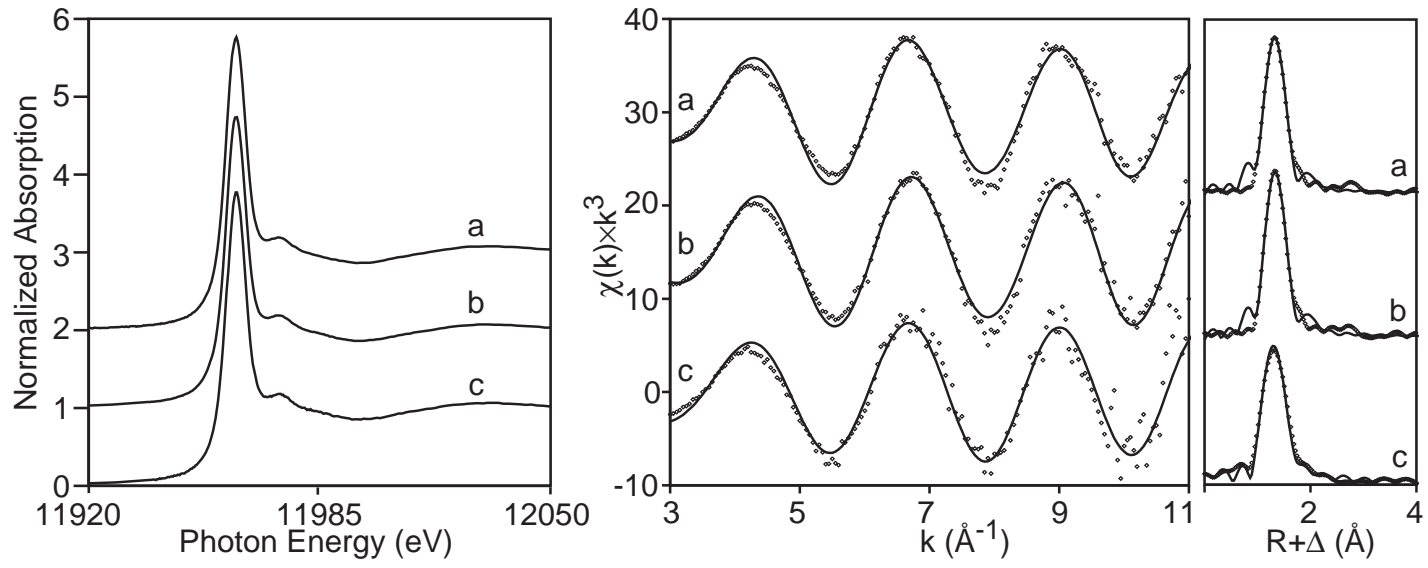

Figure 1. Re $\mathrm{L}_{2}$ XANES spectra (left), EXAFS spectra (center) and Fourier Transforms (right) for Re(VII) in glass (a) WVT-G-126b, (b) BLG-G-113a, (c) II-205. Data are depicted as points; fit is indicated by the solid line. Fit range: $3<\mathrm{k}<11 ; 0.8<\mathrm{R}<2.5$.

Table 4: EXAFS parameters for Re(VII) in glass $\left(\mathrm{S}_{0}{ }^{2}=1\right)$

\begin{tabular}{lccccc}
\hline \multicolumn{1}{c}{ Sample } & $\Delta \mathrm{E}_{0}(\mathrm{eV})$ & R-factor $^{\mathrm{a}}$ & $\begin{array}{c}\# \text { of } \mathrm{O} \\
\text { neighbors }\end{array}$ & $\mathrm{R}(\AA)$ & $\sigma^{2}\left(\AA^{2}\right)$ \\
\hline $\mathrm{NH}_{4} \mathrm{ReO}_{4}$ & $6(4)$ & 0.038 & $4(1)$ & $1.73(1)$ & $0.002(2)$ \\
$\mathrm{II}-205$ & $2(3)$ & 0.023 & $4.7(8)$ & $1.75(1)$ & $0.002(1)$ \\
WVT-G-126b & $-2(3)$ & 0.031 & $4.5(8)$ & $1.73(1)$ & $0.003(1)$ \\
WVT-G-125c & $-1(2)$ & 0.015 & $4.1(5)$ & $1.72(1)$ & $0.002(1)$ \\
WVT-G-150a & $0(2)$ & 0.008 & $4.3(6)$ & $1.73(1)$ & $0.003(1)$ \\
BLG-G-113a & $1(3)$ & 0.018 & $4.3(9)$ & $1.73(1)$ & $0.002(1)$ \\
BLG-G-85b & $5(1)$ & 0.012 & $4.5(9)$ & $1.74(1)$ & $0.001(1)$ \\
\hline
\end{tabular}

a) $\mathrm{R}$-factor $=\sum\left(\mathrm{y}_{\mathrm{i}}(\text { data })-\mathrm{y}_{\mathrm{i}}(\text { fit })\right)^{2} / \sum\left(\mathrm{y}_{\mathrm{i}}(\text { data })\right)^{2}$

The identities of the metallic Tc and Re species in the glass, $\operatorname{Tc}(0)$ and $\operatorname{Re}(0)$, were determined from the EXAFS spectra of the LAWA and LAWC glass samples prepared under highly reducing conditions generated using a 1:1 $\mathrm{CO} / \mathrm{CO}_{2}$ atmosphere. In both cases, a metallic film formed on the surface of the glass sample. The Tc K edge and Re $\mathrm{L}_{2}$ edge EXAFS spectra of these samples are shown in Figure 2. The distances determined from fitting the EXAFS are in good agreement with the hcp structure of the metals. ${ }^{32,33}$ Both samples are actually Tc/Re alloys: sample II-216 has a Tc/Re ratio of 6:1 and sample II-214 has a ratio of 1:3. Since II-216 contains mainly Tc in the metallic phase, it is referred to as Tc(0), and II-214 is referred to as Tc/Re. The very different appearance of the spectra of II-214, compared with that of II-216, is due to the 
Ramsauer-Townsend effect, which makes peaks corresponding to the scattering from Re atoms appear to be split. ${ }^{34}$ Despite the difference in appearance of the spectra, the structural parameters derived from the fitting the spectra are very similar in both samples. The EXAFS data are otherwise unremarkable. Most importantly, the lack of a peak at $\mathrm{R}<2$ shows that no $\mathrm{O}$ neighbors are present in either the Re or Tc coordination environment.

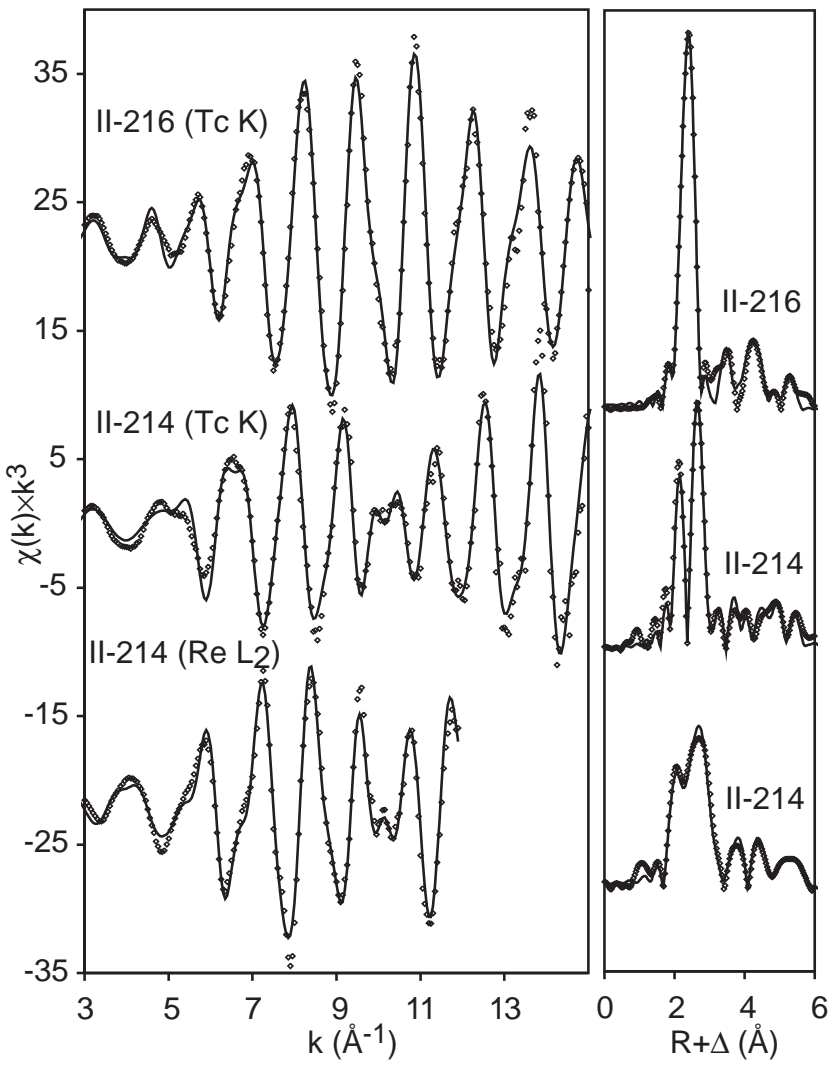

Figure 2: EXAFS spectrum and Fourier transform for Tc and Re metal standards: II-216 is the $\mathrm{Tc}(0)$ standard and II-214 is $\operatorname{Re}(0)$ standard. Data are indicated by points; fit is indicated by the solid line. Fit range, Tc K edge: $3<\mathrm{k}<15 ; 1.9<\mathrm{R}<6$; $\mathrm{Re} \mathrm{L}_{2}$ edge: $3<\mathrm{k}<11.8 ; 1.2<\mathrm{R}<5.9$. Note: the Re $L_{2}$ edge EXAFS are truncated at $12 \AA^{-1}$ due to the presence of the $R e L_{1}$ edge at $12527 \mathrm{eV}$.

The XANES spectra of the standards are shown in Figure 3 along with the XANES spectra of Tc and Re metal foils. Although the Tc K-edge XANES spectra of metallic Tc in glass, Tc(0) (II216) and Tc/Re alloy (II-214), are similar to the spectrum of bulk Tc metal, the spectra are not identical. In particular, the intensity of the transition at the absorption edge is slightly larger in the $\operatorname{Tc}(0)$ and Tc/Re alloy spectra than in Tc-foil, and the position of the feature at $\sim 21125 \mathrm{eV}$ changes as a function of the Re contents of the alloy. In contrast, the Re $\mathrm{L}_{2}$-edge XANES spectra of Re foil and Tc/Re are significantly different. Compared to the XANES spectrum of Re foil, the white line of the Tc/Re XANES spectrum is significantly larger although the edge shift is only slightly different from that of Re foil (11957.6 eV versus $11958.2 \mathrm{eV}$ ). The white line is due to the $2 \mathrm{p}_{1 / 2}$ to $6 \mathrm{~d}_{3 / 2}$ transition, and its intensity is proportional the number of vacancies in the $6 \mathrm{~d}_{3 / 2}$ level. ${ }^{35}$ In a Tc/Re alloy, the intensity of this transition is expected to be greater than in pure Re metal. Tc is more electronegative than Re and will lower the Fermi level at Re in a Tc/Re 
alloy relative to Re in the metal, which would create more vacancies in the $6 \mathrm{~d}_{3 / 2}$ level of the Tc/Re alloy. This effect has been previously observed in Pt alloys. ${ }^{35,} 36$ Apart from the intensity of the white lines, the XANES spectra of Re foil and Tc/Re in glass are similar.

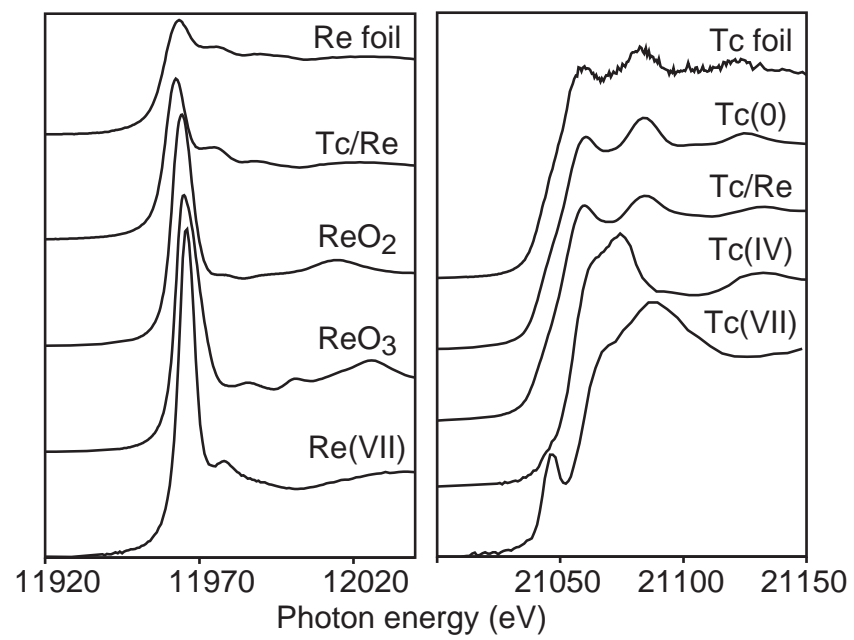

Figure 3: Re $\mathrm{L}_{2}$-edge XANES standard spectra (left) and Tc K-edge standard spectra (right) used to determine Re and Tc speciation in glass samples. Tc(0), Tc/Re, and $\operatorname{Re}(\mathrm{VII})$ correspond to II-216, II-214, and II-205, respectively.

Rhenium speciation in melter glasses. As noted in the introduction, $R e$ is used as a non-radioactive surrogate for Tc in large-scale melter studies to avoid the hazards created by Tc volatilization. For this reason, the redox state and Re speciation in a series of Re-containing nuclear waste glasses prepared in a large melter were examined. The results from fitting the EXAFS spectra of these samples are reported in Table 4. In all cases, the number of oxygen neighbors and the Re-O bond lengths are consistent with the presence of only Re(VII). In both $\mathrm{ReO}_{2}$ and $\mathrm{ReO}_{3}$, the Re center has six oxygen neighbors, and the Re-O distances are much longer, $2.00 \AA$ and $1.87 \AA$, respectively, while in $\mathrm{ReO}_{4}^{-}$, the Re center has only four oxygen neighbors and a shorter Re-O distance as seen in Table $4 .^{37,38}$ The results from fitting the XANES spectra are reported in Table 5. Both techniques show that the only important Re species in these samples is Re(VII), which is not surprising in light of the anticipated stability of $\operatorname{Re}(\mathrm{VII})$ in alkali rich glass melts suggested by its aqueous reduction potential under alkaline conditions, $-0.59 \mathrm{~V}$ at $\mathrm{pH} 14$. 
Table 5: Re speciation in melter glass samples determined from analysis of the Re $L_{2}$ XANES spectra

\begin{tabular}{lcccc}
\hline \multicolumn{1}{c}{ Sample } & Type & $\begin{array}{c}\mathrm{Fe}(\mathrm{II}) / \\
\Sigma \mathrm{Fe}\end{array}$ & $\operatorname{Re}(0)$ & $\operatorname{Re}(\mathrm{VII})$ \\
\hline WVT-G-128b & AZ-102 & 0.019 & 0 & $0.985(6)$ \\
WVT-G-126b & AZ-102 & 0.043 & 0 & $0.965(2)$ \\
WVT-G-125c & AZ-102 & 0.108 & 0 & $0.982(3)$ \\
WVT-G-150a & AZ-102 & 0.034 & 0 & $0.971(3)$ \\
BLG-G-113a & LAWA1 & 0.105 & $0.025(8)$ & $0.967(5)$ \\
BLG-G-79a & LAWA1 & 0.128 & 0 & $0.986(5)$ \\
BLG-G-85b & LAWA1 & 0.058 & 0 & $0.989(4)$ \\
\hline
\end{tabular}

Technetium and rhenium speciation in crucible glasses. The Tc and Re species present in the glasses were determined by fitting the XANES spectra of the samples using a linear combination of the XANES spectra of the standard species shown in Figure 3. The XANES spectra and fits for the glass samples are shown in Figure 4, and the fitting results are given in Table 6 along with redox potential (as $\mathrm{Fe}(\mathrm{II}) / \Sigma \mathrm{Fe}$ ) for each sample. These results show that $\mathrm{Tc}(0), \mathrm{Tc}(\mathrm{IV})$, and $\mathrm{Tc}(\mathrm{VII})$ may be observed in the samples, depending upon the redox conditions present during vitrification. In marked contrast, the results from fitting the Re $\mathrm{L}_{2}$ XANES spectra show that only $\operatorname{Re}(0)$ and $\operatorname{Re}(\mathrm{VII})$ are present. The fraction of $\operatorname{Re}(\mathrm{IV})$ or $\operatorname{Re}(\mathrm{VI})$ observed in any of the samples was not statistically different from zero. The absence of these oxidation states is most obvious in sample II-212, which contains both $\operatorname{Re}(0)$ and $\operatorname{Re}(\mathrm{VII})$ but not $\operatorname{Re}(\mathrm{IV})$ or $\operatorname{Re}(\mathrm{VI})$. 


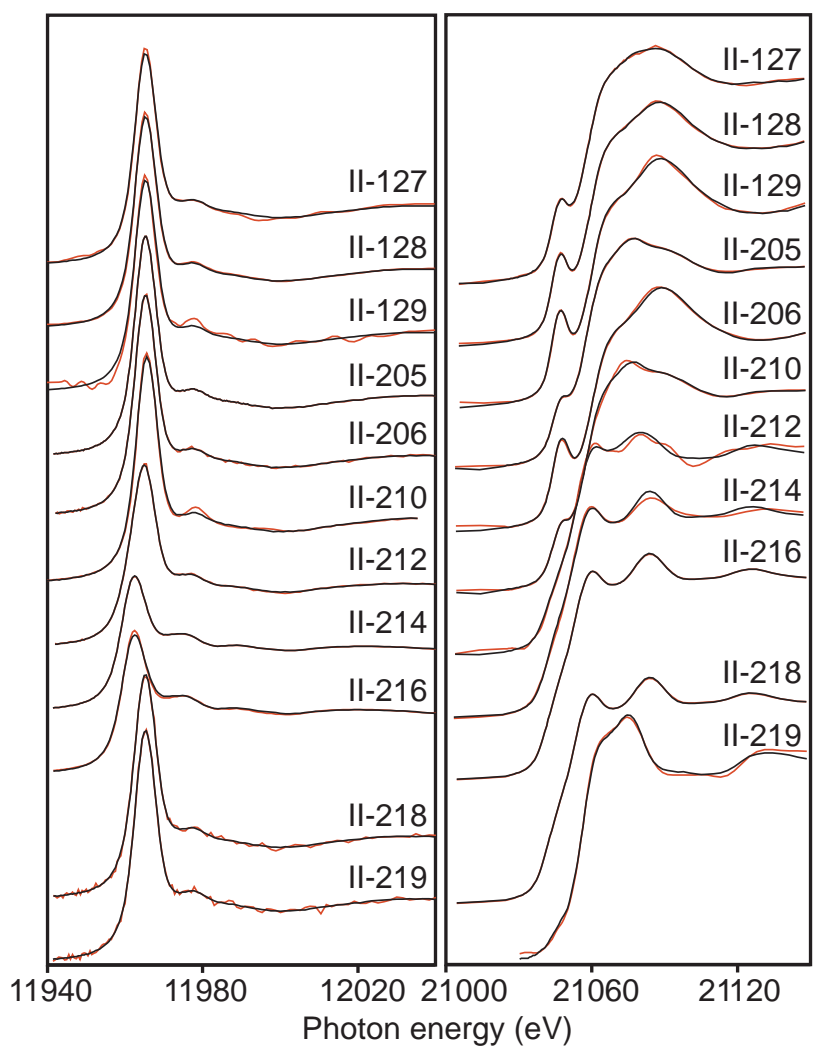

Figure 4: XANES spectra (red) and fits (black) for glass samples at the Re L2-edge (left) and Tc K-edge (right). Sample numbers are given above the corresponding spectrum.

Table 6: Tc and Re speciation in crucible glass samples determined by XANES analysis

\begin{tabular}{ccccccc}
\hline Sample & $\begin{array}{c}\mathrm{Fe}(\mathrm{II}) / \\
\mathrm{FFe}^{\mathrm{a}}\end{array}$ & $\operatorname{Re}(0)$ & $\operatorname{Re}(\mathrm{VII})$ & $\mathrm{Tc}(0)$ & $\mathrm{Tc}(\mathrm{IV})$ & $\mathrm{Tc}(\mathrm{VII})$ \\
\hline II-118 & 0.119 & $\mathrm{~b}$ & $\mathrm{~b}$ & 0 & $0.21(1)$ & $0.80(1)$ \\
II-121 & 0.237 & $\mathrm{~b}$ & $\mathrm{~b}$ & 0 & $0.78(3)$ & $0.17(4)$ \\
$\mathrm{II}-127$ & 0.139 & 0 & $0.98(1)$ & $0.06(1)$ & $0.27(1)$ & $0.67(1)$ \\
II-128 & 0.081 & 0 & $0.98(1)$ & 0 & $0.13(1)$ & $0.87(1)$ \\
II-129 & 0.089 & 0 & $0.98(2)$ & 0 & 0 & $1.00(1)$ \\
II-205 & 0.223 & 0 & $1^{\mathrm{c}}$ & 0 & $0.47(1)$ & $0.52(1)$ \\
II-206 & 0.179 & 0 & $1.00(1)$ & 0 & 0 & $1.00(2)$ \\
II-210 & 0.162 & 0 & $1.02(3)$ & 0 & $0.48(2)$ & $0.51(3)$ \\
II-212 & 0.988 & $0.41(1)$ & $0.63(1)$ & $0.78(5)$ & $0.23(4)$ & 0 \\
II-214 & 0.998 & $1^{\mathrm{c}}$ & 0 & $1.00(1)$ & 0 & 0 \\
II-216 & 0.994 & $1.05(1)$ & 0 & $1^{\mathrm{c}}$ & 0 & 0 \\
II-218 & 0.843 & $0.09(3)$ & $0.98(2)$ & $1.00(1)$ & 0 & 0 \\
II-219 & 0.283 & 0 & $1.05(1)$ & 0 & $1.00(4)$ & 0 \\
\hline
\end{tabular}

a) Standard deviation: $2 \%$ of the value, determined from duplicate measurements

b) Sample contains no Re

c) Spectrum used as a standard in fitting 


\section{Discussion}

The redox environment of the crucible glasses is a function of both the atmosphere under which the glasses were prepared and the composition of the mixture used to prepare the glass, which contains both organic compounds that create reducing conditions and high concentrations of nitrate that create oxidizing conditions during vitrification of the samples. From this standpoint, the main difference between the LAWA and LAWC glasses is that the LAWC waste surrogate contains a higher concentration of organic compounds, which produces a more reducing environment than the LAWA glasses during vitrification.

The speciation of Tc in glasses is expected to vary with oxygen fugacity, $\mathrm{fO}_{2}$, during the preparation of the glass since the Tc species present in the glass are in equilibrium with $\mathrm{O}_{2}$, as shown in Eq. 1, where $\mathrm{n}$ is the charge of the oxidized species and $\mathrm{m}$ is the difference in the number of electrons in the two oxidation states. ${ }^{39-41}$ Schreiber and coworkers showed that this equilibrium can also be represented by Eq. 2, where $\mathrm{E}^{*}$ is the $-\log \left(f \mathrm{O}_{2}\right)$ at which the concentrations of the two oxidation states are equal, to obtain a straightforward relationship between the $\mathrm{fO}_{2}$ and the redox state of the metal ion. ${ }^{40}$ This equilibrium is obeyed by a wide variety transition metals in borosilicate glasses prepared by equilibrating the glass melt with an atmosphere of known $\mathrm{fO}_{2}$. Using these results, $\mathrm{fO}_{2}$ for glasses listed in Table 6 can be determined from Eq. 2 and the measured ratio of $\mathrm{Fe}(\mathrm{II})$ to $\mathrm{Fe}(\mathrm{III})$ in the glass. The ratio of $\mathrm{Tc}(\mathrm{IV})$ to $\mathrm{Tc}(\mathrm{VII})$ as a function of $\mathrm{fO}_{2}$ can then be compared as shown in Figure 5 for samples that contain observable quantities of Tc(IV) and Tc(VII).

$$
\begin{gathered}
4 \mathrm{M}_{\text {melt }}^{\mathrm{n}+}+2 \mathrm{mO}_{\text {melt }}^{2-} \longleftrightarrow 4 \mathrm{M}_{\text {melt }}^{(\mathrm{n}-\mathrm{m})+}+\mathrm{mO}_{2 \text { (gas) }} \\
-\log \left(\mathrm{fO}_{2}\right)=\frac{4}{\mathrm{~m}} \log \left(\frac{\left[\mathrm{M}^{(\mathrm{n}-\mathrm{m})+}\right]}{\left[\mathrm{M}^{\mathrm{n}+}\right]}\right)+\mathrm{E}^{*}
\end{gathered}
$$

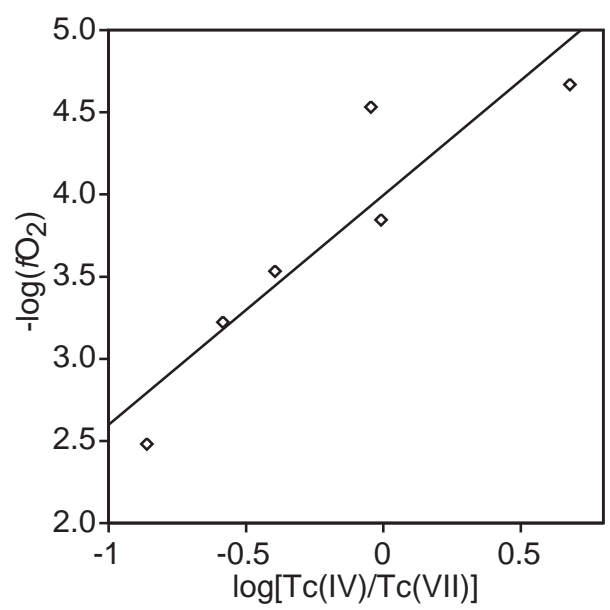

Figure 5. Relationship of Tc redox state to oxygen fugacity determined from Fe(II)/ $\Sigma \mathrm{Fe}$. Data are indicated by diamonds and the least-squares fit is indicated by the solid line. 
The data shown in Figure 5 are consistent with the anticipated behavior of Tc(VII) and Tc(IV) in the glass. The least-squares linear fit to the data has a slope of 1.4 versus the expected value of $4 / 3$, and $E^{*}$ is 4.0 . The value of $E^{*}$ may be compared to previous work in a somewhat different system by Freude, et al. in which the reduction potential, $\mathrm{E}_{0}$ ' of the $\mathrm{Tc}(\mathrm{VII}) / \mathrm{Tc}(\mathrm{IV})$ couple was determined to be $-0.18 \mathrm{~V}$ in a borosilicate melt at $1000{ }^{\circ} \mathrm{C}$ by square wave voltammetry. ${ }^{19}$ The relationship between $\mathrm{E}^{*}$ and $\mathrm{E}_{0}$ ' is given by $\mathrm{Eq} .3$,

$$
E^{*}=\left(\frac{-4 F}{R \ln (10)}\right) \frac{E_{0}^{\prime}}{T}-\log (0.21)
$$

where $\mathrm{F}$ is the Faraday constant, $\mathrm{R}$ is the gas constant, and $\mathrm{T}$ is the absolute temperature. The value measured by voltammetry, $\mathrm{E}_{0}{ }^{\prime}=-0.18 \mathrm{~V}$ at $1000{ }^{\circ} \mathrm{C}$, is equivalent to $\mathrm{E}^{*}=3.6$, which is in good agreement with the value obtained here. It should be noted that $\mathrm{E}^{*}$ for Tc is expected to change somewhat as the glass sample cools since the $\mathrm{Tc}(\mathrm{IV}) / \mathrm{Tc}(\mathrm{VII})$ couple has a different potential than the $\mathrm{Fe}(\mathrm{II}) / \mathrm{Fe}(\mathrm{III})$ couple, ${ }^{42}$ which is consistent with the slightly higher value of $\mathrm{E}^{*}$ determined here: $\mathrm{E}_{0}$ ' of $-0.18 \mathrm{~V}$ is equal to $\mathrm{E}^{*}=4.0$ at $825{ }^{\circ} \mathrm{C}$. Overall, the behavior of the $\mathrm{Tc}(\mathrm{IV}) / \mathrm{Tc}(\mathrm{VII})$ couple in the crucible glasses is consistent with the $\mathrm{fO}_{2}$ present during the formation of the melt as determined from the $\mathrm{Fe}(\mathrm{II}) / \mathrm{Fe}(\mathrm{III})$ ratio in the resulting glass.

As anticipated from their reduction potentials, Re(VII) is more stable towards reduction in the glass than is $\mathrm{Tc}(\mathrm{VII})$. This difference limits the conditions under which Re is a good surrogate for Tc. For Fe(II) $/ \Sigma \mathrm{Fe}<\sim 0.1$, the speciation of Tc and Re is similar since $>90 \%$ of both elements are heptavalent under these relatively oxidizing conditions. Similarly, for $\mathrm{Fe}(\mathrm{II}) / \Sigma \mathrm{Fe}>0.95$, the speciation of Tc and Re is again identical as both elements are present as the metal; however, such highly reducing conditions are not very relevant to nuclear waste glass. Between these extremes, the Re and Tc species present in the glass are generally quite different. As noted above, a difference in speciation is anticipated because of the difference between the reduction potentials of Re(VII) and Tc(VII), and the speciation of Tc and Re reflects this difference. When the speciation of Tc and Re are different, the average oxidation state of the Tc species is lower than that of the Re species, as expected. However, Tc and Re do not behave congruently as a function of redox state.

In particular, neither $\operatorname{Re}(\mathrm{IV})$ nor $\operatorname{Re}(\mathrm{VI})$ appears to be stable in the glass. In contrast, the behavior of Tc is quite different as Tc(0), Tc(IV), and Tc(VII) all appear to be stable. This difference between the behavior of Tc and Re was unanticipated. It had been assumed that the speciation of Re in glasses created under more reducing conditions would mimic the speciation of Tc in glasses created under more oxidizing conditions. However, the observation that only $\operatorname{Re}(0)$ and $\operatorname{Re}(\mathrm{VII})$ are present in the glass shows that Re may not be a good surrogate for Tc under certain redox conditions, namely $0.1<\mathrm{Fe}(\mathrm{II}) / \Sigma \mathrm{Fe}<0.95$.

The failure to observe $\operatorname{Re}(\mathrm{IV})$ and $\mathrm{Re}(\mathrm{VI})$ in these samples suggests that these species might not be stable under conditions present in the melter. Evaluation of this hypothesis is hampered by a lack of thermodynamic data, especially for M(IV) dissolved in the glass melt, where $\mathrm{M}=\mathrm{Tc}$ or Re. However, the stability of $\operatorname{Re}(\mathrm{IV})$ and $\mathrm{Tc}(\mathrm{IV})$ in the melt can be approximated using 
thermodynamic parameters of the tetravalent compounds $\mathrm{ReO}_{2}$ and $\mathrm{TcO}_{2}$. For the purposes of this discussion, two disproportionation reactions, Eqs. 4 and 5, are of interest. The first is disproportionation of $\mathrm{M}(\mathrm{IV})$ to $\mathrm{M}(0)$ and $\mathrm{M}(\mathrm{VII})$, which has already been analyzed in detail by Migge. ${ }^{11,12}$ Since the glass melt is sodium-rich, the second reaction may be a better approximation of the behavior of Tc and Re in the melt.

$$
\begin{aligned}
& 7 \mathrm{MO}_{2} \rightarrow 3 \mathrm{M}+2 \mathrm{M}_{2} \mathrm{O}_{7}(\mathrm{~g}) \\
& 7 \mathrm{MO}_{2}+2 \mathrm{Na}_{2} \mathrm{SiO}_{3} \rightarrow 3 \mathrm{M}+2 \mathrm{SiO}_{2}+4 \mathrm{NaMO}_{4}
\end{aligned}
$$

A plot of the Gibbs free energy of reaction 5 as a function of temperature is given in Figure $6 .{ }^{43}$ A number of assumptions were necessary to calculate the energy of reaction 5 . The heat capacities of $\mathrm{NaTcO}_{4}$ and $\mathrm{TcO}_{2}$ were assumed to be the same as those of $\mathrm{NaReO}_{4}$ and $\mathrm{ReO}_{2}$, and the heat capacity of Re was assumed to be the same as W since the heat capacity of Re at high temperature was not available. However, the main assumption is that reaction 5 is a good approximation of the behavior of these species in the glass melt. Because of the last assumption in particular, the trends shown in Figure 6 are qualitative rather than quantitative. Nevertheless, the trends shown in Figure 6 are consistent with the observed behavior of Tc and Re in this study as well as with previous observations. In particular, the previous voltammetric study of the behavior of Tc and Re in glass showed that two reduction peaks were present in the Tc system, which could be assigned to the $\mathrm{Tc}(\mathrm{VII}) / \mathrm{Tc}(\mathrm{IV})$ and $\mathrm{Tc}(\mathrm{IV}) / \mathrm{Tc}(0)$ couples. However, in the Re system, only one reduction peak was observed at all square-wave frequencies. This observation was explained by a superposition of the $\operatorname{Re}(\mathrm{VII}) / \operatorname{Re}(\mathrm{IV})$ and $\operatorname{Re}(\mathrm{IV}) / \operatorname{Re}(0)$ couples and the suggestion that $\operatorname{Re}(\mathrm{IV})$ was unstable under these conditions was forwarded. Previous thermochemical calculations of the rhenium-oxygen system also have suggested that $\operatorname{Re}(\mathrm{IV})$ may be unstable under these conditions. ${ }^{11,12}$

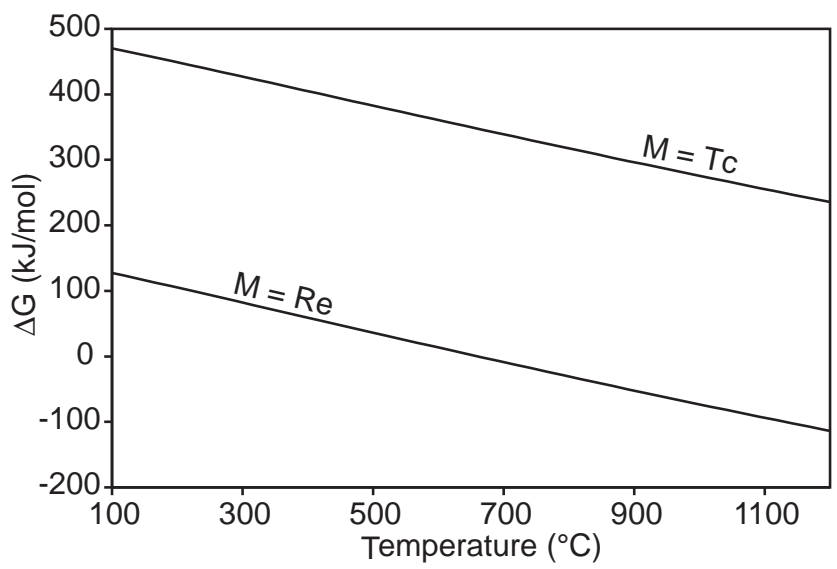

Figure 6. Plot of the Gibbs free energy of reaction 5 as a function of temperature. Disproportionation of Re(IV) becomes exothermic at high temperature.

\section{Conclusions}

The speciation of Re and Tc have been examined in a series of nuclear waste glasses prepared under different redox conditions. To a large extent, Tc behaves as expected based on its known chemistry. On the other hand, Re behaves very differently under these conditions, and $\operatorname{Re}(\mathrm{IV})$ 
appears to be unstable with respect to disproportionation. Calculation of the Gibbs free energy of the disproportionation reaction using the thermodynamic values of $\mathrm{ReO}_{2}$ and $\mathrm{TcO}_{2}$ as estimates for those of $\operatorname{Re}(\mathrm{IV})$ and $\mathrm{Tc}(\mathrm{IV})$ dissolved in the melt suggests that $\operatorname{Re}(\mathrm{IV})$ will disproportionate at high temperatures but Tc(IV) will be stable. This difference limits the applicability of Re as a Tc surrogate. While Re is a good surrogate for Tc under oxidizing conditions, it is a poor surrogate for Tc under even slightly reducing conditions, including those intended to limit Tc volatility by converting volatile $\mathrm{Tc}(\mathrm{VII})$ into less volatile $\mathrm{Tc}(\mathrm{VI})$. It should be noted that these conclusions are only valid for the borosilicate glasses examined in this study, and Tc and Re may behave differently in other glasses, such as iron phosphate glasses. 


\section{Raman Studies of Technetium in Borosilicate Waste Glass} Introduction

Raman measurements were made on seven borosilicate glasses containing Tc and their Tc-free counterparts to determine the utility of this technique to detect Tc in waste glasses and to complement previous X-ray absorption spectroscopy (XAS) investigations. ${ }^{45}$

Raman spectroscopy may be able to detect pertechnetate at relatively low concentrations in borosilicate materials. Borosilicate glasses, such as waste glasses designed for radioactive waste encapsulation, have relatively weak Raman cross-sections. In contrast, the Raman cross-section of pertechnetate is large. ${ }^{46}$

Raman studies of Tc have concentrated on aqueous solutions and crystalline oxides containing pertechnetate anions. ${ }^{46,47}$ Raman-active modes from pertechnetate tetrahedra are grouped in two pairs centered near 320 and $910 \mathrm{~cm}^{-1}$; 47 these peaks are relatively narrow having 20 to $40 \mathrm{~cm}^{-1}$ widths. The more intense of the two pertechnetate peaks, near $910 \mathrm{~cm}^{-1}$, is due to symmetric and asymmetric Tc-O stretch modes within $\mathrm{TcO}_{4}{ }^{-}$tetrahedra ( $v_{1}$ and $v_{3}$, respectively). ${ }^{47}$ The weaker pertechnetate peak, near $320 \mathrm{~cm}^{-1}$, is due to symmetric and asymmetric O-Tc-O bend modes $\left(v_{2}\right.$ and $v_{4}$, respectively). ${ }^{47}$ Due to its relatively large Raman intensity, the $910 \mathrm{~cm}^{-1}$ peak area may be useful for the quantitative determination of the pertechnetate concentration. Similar to the behavior of sulfate Raman-active modes in crystalline and amorphous oxides, ${ }^{48}$ the frequency of the $v_{1}$ pertechnetate mode may be sensitive to cation bonding around $\mathrm{TcO}_{4}{ }^{-}$tetrahedra in various crystalline compounds. ${ }^{46}$ In view of the lack of information in the literature about Raman modes for reduced Tc species, the Raman sensitivity may be poor for $\mathrm{Tc}^{4+}$ in waste glasses.

Raman studies of borosilicate waste glasses (for example, ref. ${ }^{49}$ ) show that most spectral features are assigned to vibrational modes from the borosilicate network. These features are typically broad and have widths greater than $100 \mathrm{~cm}^{-1}$. Bands near $1400 \mathrm{~cm}^{-1}$ are assigned to B-O stretch modes within $\mathrm{BO}_{3}$ units. Contributions to bands between 800 and $1200 \mathrm{~cm}^{-1}$ are dominated by T-O stretch motions within tetrahedra, where T is typically Si or Al. The broad envelope at frequencies below $800 \mathrm{~cm}^{-1}$ is assigned to delocalized displacements that include Si$\mathrm{O}-\mathrm{Si}$ bend, as well as longer-range motions within rings that are made up of various numbers of linked tetrahedra.

\section{Experimental details}

A $0.106 \mathrm{M}$ pertechnetate solution, prepared by dissolving ammonium pertechnetate in dilute nitric acid, was used for Raman spectral comparisons with the Tc-containing glasses investigated. Reagent-grade chemical compounds were used for the glasses synthesized (Table 7); glass synthesis details are discussed in the previous section. Compositions for these glasses were determined by X-ray fluorescence spectroscopy (XRF) of the solid samples and by direct coupled plasma atomic emission spectroscopic (DCP-AES) analyses of acid-digested samples (Table 7). All glass samples used for Raman measurements were irregular shards with conchoidal fracture surfaces and were determined to be crystal-free by X-ray diffraction. All glasses were synthesized by melting at temperatures near $1150{ }^{\circ} \mathrm{C}$, except for the more silica-rich I-283 glasses (Table 7), which required a higher melting temperature near $1250{ }^{\circ} \mathrm{C}$. The Tc-free I-283Tc0 glass was found to contain a small amount of unreacted reagent; Raman and XRF 
measurements were made solely on the glassy portions of this sample. The higher melting temperatures and resulting undissolved reagents in the I-283Tc0 glass lead to larger composition differences with respect to I-283 glass (Table 7). Spectral differences between I-283Tc0 glass and I-283 glass (Figure 8b) are consistent with I-283Tc0 glass being $\mathrm{Na}_{2} \mathrm{O}$-rich and slightly $\mathrm{SiO}_{2}$-poor compared with I-283 glass.

Table 7. Major oxide components of the standard glasses from XRF analyses (wt.\%); uncertainties are $\pm 4 \%$ of the values listed. Tc values are from liquid scintillation measurements; uncertainties are $\pm 5 \%$ of the values listed; Tc species determined from Tc XANES fitting. ${ }^{1} \mathrm{~B}_{2} \mathrm{O}_{3}$ and $\mathrm{Li}_{2} \mathrm{O}$ values are from DCP analyses. "Other” indicates other components that include: $\mathrm{Cl}$, $\mathrm{Cr}_{2} \mathrm{O}_{3}, \mathrm{CuO}, \mathrm{F}, \mathrm{MnO}, \mathrm{NiO}, \mathrm{P}_{2} \mathrm{O}_{5}, \mathrm{SO}_{3}, \mathrm{SrO}, \mathrm{TiO}_{2}, \mathrm{ZnO}$, and $\mathrm{ZrO}_{2}$. * indicates the value is from the target composition.

\begin{tabular}{|c|c|c|c|c|c|c|c|}
\hline Glass & Tc & $\begin{array}{l}\text { Network } \\
\text { Modifiers }\end{array}$ & $\mathrm{Fe}_{2} \mathrm{O}_{3}$ & $\mathbf{A l}_{2} \mathbf{O}_{3}$ & $\mathbf{B}_{2} \mathbf{O}_{3}$ & $\mathrm{SiO}_{2}$ & Other \\
\hline $\begin{array}{c}\text { Oxidized Standard } \\
\text { I-283 }\end{array}$ & $\begin{array}{c}0.158 \\
100 \% \mathrm{Tc}^{7+}\end{array}$ & $\begin{array}{c}\mathrm{Na}_{2} \mathrm{O} 14.34 \\
\mathrm{CaO} 4.35\end{array}$ & 0.07 & 14.24 & 6.23 & 60.51 & 0.15 \\
\hline I-283 Tc0 & 0 & $\begin{array}{c}\mathrm{Na}_{2} \mathrm{O} 17.23 \\
\mathrm{CaO} 4.65\end{array}$ & 0.07 & 14.48 & $4.00 *$ & 59.20 & 0.0 \\
\hline $\begin{array}{l}\text { Reduced Standard } \\
\text { II-13 }\end{array}$ & $\begin{array}{c}0.070 \\
100 \% \mathrm{Tc}^{4+}\end{array}$ & $\begin{array}{cc}\mathrm{Na}_{2} \mathrm{O} & 15.14 \\
\mathrm{MgO} & 1.97 \\
\mathrm{~K}_{2} \mathrm{O} & 1.51 \\
\mathrm{CaO} & 2.03\end{array}$ & 6.21 & 7.31 & 12.10 & 44.61 & 8.71 \\
\hline II-13 Tc0 & 0 & $\begin{array}{cc}\mathrm{Na}_{2} \mathrm{O} & 14.79 \\
\mathrm{MgO} & 2.06 \\
\mathrm{~K}_{2} \mathrm{O} & 1.49 \\
\mathrm{CaO} & 2.10\end{array}$ & 6.00 & 7.25 & $12.10 *$ & 45.15 & 8.91 \\
\hline
\end{tabular}

Raman spectra were measured for the pertechnetate solution and glass fragments using a single grating spectrograph-notch filter system. ${ }^{50}$ An EXCEL Model $3000 \mathrm{Ar}^{+}$laser provided the $5145 \AA$ wavelength incident light that was directed through a broad band polarization rotator (Newport Model PR-550) to the laser microscope which guided the laser light down to the sample surface through a long working distance Mitutoyo 10x microscope objective. The laser light was focused to a $10 \mu \mathrm{m}$ diameter spot on each sample. To eliminate $\beta$-radiation exposure from each Tc-containing sample measured, the solution and glass fragments were encapsulated within small silica glass vials so that the incident laser light could probe into and the scattered light intensities could be recorded through the vial walls. The laser light power was approximately $25 \mathrm{~mW}$ at the sample. Room temperature polarized spectra were gathered in back-scattering geometry. The scattered light was directed through an analyzer polarizer in the microscope column that was set to one orientation for all polarized spectra collected. After the analyzer, the scattered light proceeded through holographic notch and super-notch filters (Kaiser Optical Systems), which reduced the Rayleigh scattered light intensity by ten optical densities. The notch filters were oriented in the scattered light path so that the filter cut-off frequency was 
minimized to near $60 \mathrm{~cm}^{-1}$ from the laser line. Due to the relatively broad spectral features for these samples, the incident slits of the JY-Horiba HR460 spectrograph were set to $6 \mathrm{~cm}^{-1}$ resolution. The spectrograph used a 1200 line/mm grating (Richardson Grating Laboratory) that was set to disperse the Stokes scattered light from the sample on to a 2048 x 512 element Peltier cooled CCD detector (Model DU440BV, Andor Technology). The spectrograph was frequency calibrated using $\mathrm{CCl}_{4}$, so that the recorded frequencies are accurate to within $\pm 1 \mathrm{~cm}^{-1}$. Parallel-polarized (VV) or cross-polarized (HV) spectra were collected, where the incident laser light was vertically or horizontally polarized, respectively, as it entered the laser microscope. Each spectrum is an average of 10 accumulations, collected for 10 seconds each. All spectra were corrected for notch filter, grating efficiency, and detector quantum efficiency effects on the scattered light intensities (Figs. 7-11).

Two inter-related problems arise when comparing the Raman spectra of some of Tc-containing and Tc-free glasses investigated: Rayleigh scattering differences, and color differences. The Tc-containing waste glasses are slightly darker in color (brown-green) than their Tc-free base-glass counterparts. This color difference is due to the slightly higher Fe concentrations for the Tc-containing glasses (Table 7). The darker color of the Tc-containing glasses causes more Rayleigh scattering, producing the larger "Rayleigh tail” (at frequencies under $200 \mathrm{~cm}^{-1}$ ) for the II-128 and II-129 glasses than for the Tc-free LAWC22 and LAWA125 glasses (Figs. 10 and 11). The darker samples also absorb more of the incident laser light, and reduce the sample volume producing the Raman signal. As a result of the color differences, rescaling of the spectrum of a Tc-containing glass to the spectrum of the corresponding Tc-free glass was necessary so that the main spectral features coincided as closely as possible (Figs. 8b, 9-11).

\section{Results and Discussion}

Solution and Glass Standards. The Raman spectra of the pertechnetate in $\mathrm{HNO}_{3}$ solution indicates $\mathrm{TcO}_{4}{ }^{-}$tetrahedral modes near 325 and $910 \mathrm{~cm}^{-1}$ (Figure 7). ${ }^{47}$ The $910 \mathrm{~cm}^{-1}$ peak, due to Tc-O stretch modes, is strongly polarized, where the symmetric stretch mode accounts for the VV component intensity, while the asymmetric stretch mode accounts for the VH intensity. The $325 \mathrm{~cm}^{-1} \mathrm{O}$-Tc-O bend mode peak has little polarization dependence. Other peaks in the solution spectra near 718, 1047, and $1400 \mathrm{~cm}^{-1}$ are contributions from $\mathrm{HNO}_{3}$, as seen in the spectra of a Tc-free $\mathrm{HNO}_{3}$ solution.

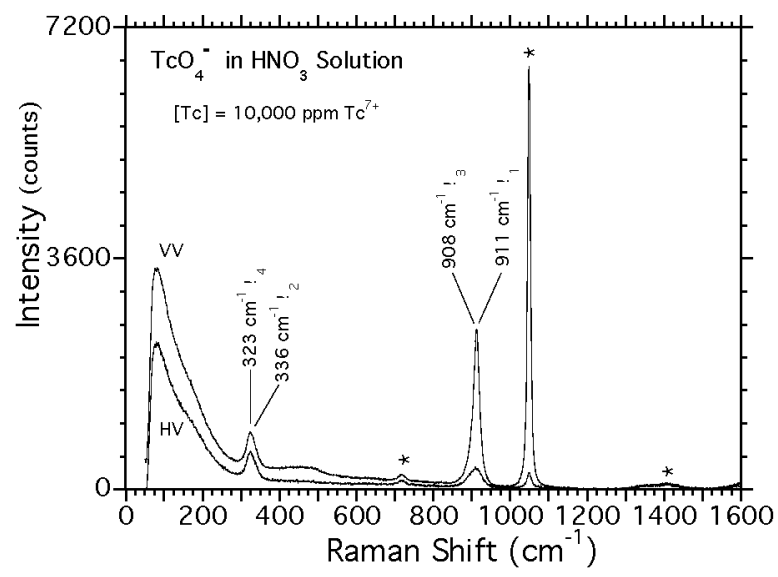


Figure 7. Polarized Raman spectra of $1 \% \mathrm{TcO}_{4}$ solution in $\mathrm{HNO}_{3}$. Pertechnetate modes $\left(v_{1}\right.$ through $v_{4}$ ) are indicated. The large, low-frequency feature is due to Rayleigh scattering; the weak, broad feature near $480 \mathrm{~cm}^{-1}$ is from the silica glass vial surrounding the solution. Features marked with an asterisk are from the $\mathrm{HNO}_{3}$ component of the solution.

Raman spectra were collected for two standard Tc-containing glasses: I-283 glass with 100\% of the Tc present as $\mathrm{Tc}^{7+}$ within pertechnetate tetrahedra, and II-13 glass with $100 \%$ of the Tc present as $\mathrm{Tc}^{4+}$ within six-coordinated oxygen environments (Figs. 7 and 8). Tc speciation and coordination information for these glasses was determined by X-ray absorption spectroscopy. ${ }^{29}$, 44 The Raman spectra of the Tc-free I-283Tc0 glass contain the broad borosilicate network features in the spectra for I-283 glass, except for the narrow 325 and $915 \mathrm{~cm}^{-1}$ peaks (Figure 8a), which have the same polarization dependence (Figure 8b) as the 325 and $910 \mathrm{~cm}^{-1}$ peaks, respectively, in the pertechnetate solution data (Figure 7). The behavior of the pertechnetate modes in the I-283 glass spectra indicates that pertechnetate tetrahedra within this glass are in environments similar to those in solution, wherein all pertechnetate anions are isolated from each other and the borosilicate network. The $100 \% \mathrm{Tc}^{4+}$ II-13 glass spectra have no Tc-dependent spectral features (Figure 9), because the spectra for II-13 glass and the Tc-free II-13Tc0 glass are nearly identical. These results show that Raman spectroscopy is sensitive to pertechnetate tetrahedra, but is insensitive to six coordinated $\mathrm{Tc}^{4+}$ environments in borosilicate glass, even at Tc concentrations near 700 ppm (see Table 7 for II-13 glass).
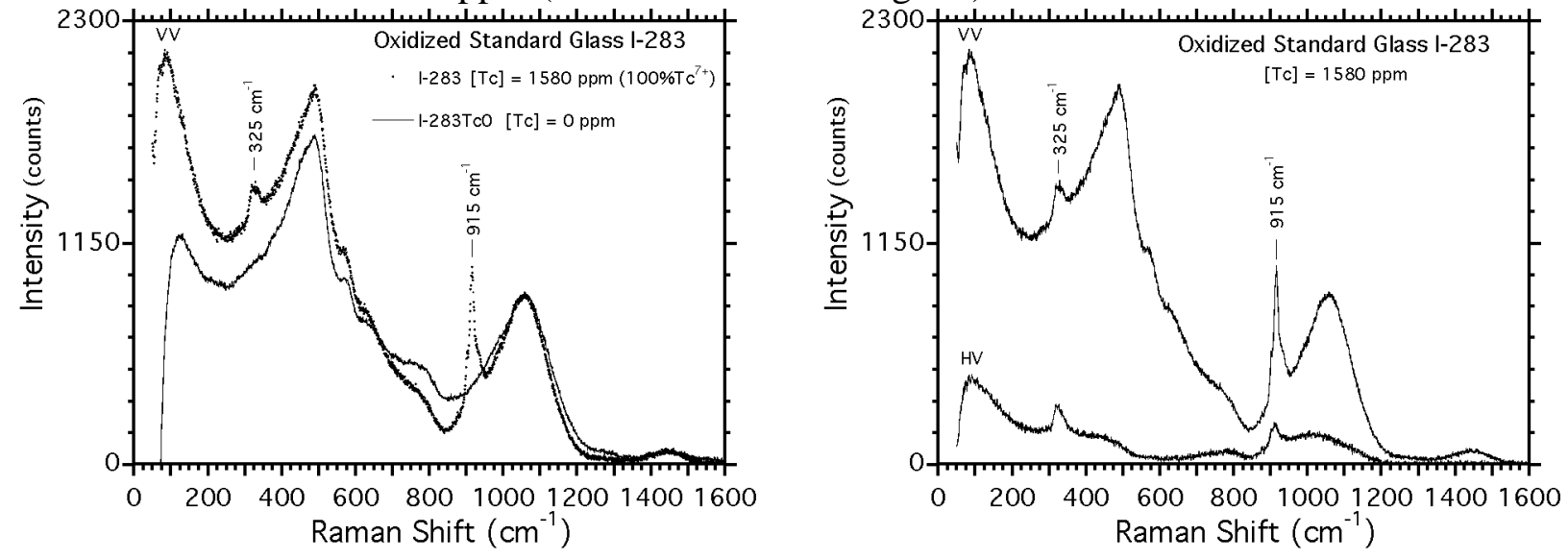

Figure 8. A) (Left panel) Parallel polarized Raman spectra of the oxidized Tc-containing I-283 glass and Tc-free I-283Tc0 glass. B) (Right panel) Polarized Raman spectra of I-283 borosilicate glass. Pertechnetate modes are indicated. 


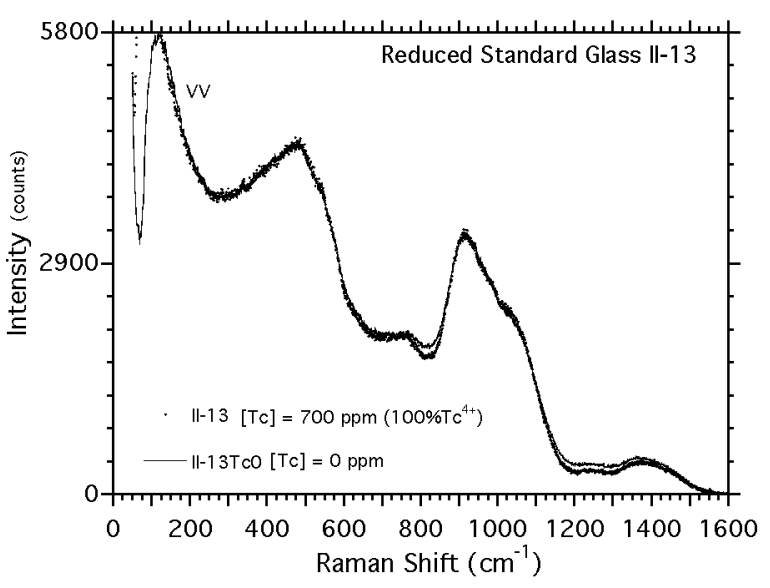

Figure 9. Parallel polarized Raman spectra of the reduced Tc-containing II-13 glass, and the Tcfree II-13Tc0 glass. No technetium related modes are observed in the II-13 glass spectrum.

Borosilicate Waste Glasses. Raman spectra were collected for five Tc-containing borosilicate waste glasses, where Tc concentrations range from 30 to $570 \mathrm{ppm}$ (Table 8), as well as their Tc-free counterparts. A variety of different Tc species distributions are also represented in these glasses: from the most oxidized glass, II-129 (Table 8) to the most reduced glass, II-121. The chemically equivalent Tc-free base-glasses include LAWA125 and LAWC22 (Table 8). These waste glasses can be divided into two groups based on their compositions: one (designated "AP-101," from the waste type) that includes Tc-containing II-118 and II-129, as well as Tc-free LAWA125; and a second (designated "AN-107”) that includes Tc-containing II-121, II-127, and II-128, as well as Tc-free LAWC22. The most Tc-rich waste glass from each of the two chemical groups is compared in Figures 10 and 11 with its Tc-free counterpart (i.e.: II-129 with LAWA125, and II-128 with LAWC22). 
Table 8. Major oxide components of the waste glasses from XRF analyses (wt.\%); uncertainties are $\pm 4 \%$. Conventions in Table 7 apply.

\begin{tabular}{|c|c|c|c|c|c|c|c|}
\hline $\begin{array}{c}\text { Glass } \\
\text { (recipe type) }\end{array}$ & Tc & $\begin{array}{l}\text { Network } \\
\text { Modifiers }\end{array}$ & $\mathrm{Fe}_{2} \mathrm{O}_{3}$ & $\mathrm{Al}_{2} \mathbf{O}_{3}$ & $\mathbf{B}_{2} \mathbf{O}_{3}$ & $\mathrm{SiO}_{2}$ & Other \\
\hline $\begin{array}{c}\text { II-118 } \\
\text { (AP-101) }\end{array}$ & $\begin{array}{c}0.005 \\
20 \% \mathrm{Tc}^{4+} \\
+ \\
80 \% \mathrm{Tc}^{7+}\end{array}$ & $\begin{array}{cc}\mathrm{Li}_{2} \mathrm{O} & 0.23 \\
\mathrm{Na}_{2} \mathrm{O} & 16.00 \\
\mathrm{MgO} & 2.06 \\
\mathrm{~K}_{2} \mathrm{O} & 2.70 \\
\mathrm{CaO} & 2.06\end{array}$ & 7.53 & 5.88 & 9.06 & 44.16 & 5.33 \\
\hline $\begin{array}{c}\text { II-121 } \\
\text { (AN-107) }\end{array}$ & $\begin{array}{c}0.003 \\
80 \% \mathrm{Tc}^{4+} \\
+ \\
20 \% \mathrm{Tc}^{7+}\end{array}$ & $\begin{array}{cc}\mathrm{Li}_{2} \mathrm{O} & 2.39 \\
\mathrm{Na}_{2} \mathrm{O} & 12.41 \\
\mathrm{MgO} & 1.69 \\
\mathrm{~K}_{2} \mathrm{O} & 0.36 \\
\mathrm{CaO} & 4.86\end{array}$ & 5.93 & 6.17 & 10.69 & 46.46 & 4.76 \\
\hline $\begin{array}{c}\text { II-127 } \\
\text { (AN-107) }\end{array}$ & $\begin{array}{c}0.048 \\
25 \% \mathrm{Tc}^{4+} \\
+ \\
75 \% \mathrm{Tc}^{7+}\end{array}$ & $\begin{array}{cc}\mathrm{Li}_{2} \mathrm{O} & 2.17 \\
\mathrm{Na}_{2} \mathrm{O} & 15.61 \\
\mathrm{MgO} & 1.58 \\
\mathrm{~K}_{2} \mathrm{O} & 0.38 \\
\mathrm{CaO} & 4.73\end{array}$ & 5.88 & 6.24 & 10.32 & 45.23 & 7.62 \\
\hline $\begin{array}{c}\text { II-128 } \\
\text { (AN-107) }\end{array}$ & $\begin{array}{c}0.057 \\
10 \% \mathrm{Tc}^{4+} \\
+ \\
90 \% \mathrm{Tc}^{7+}\end{array}$ & $\begin{array}{cc}\mathrm{Li}_{2} \mathrm{O} & 2.24 \\
\mathrm{Na}_{2} \mathrm{O} & 16.12 \\
\mathrm{MgO} & 1.63 \\
\mathrm{~K}_{2} \mathrm{O} & 0.25 \\
\mathrm{CaO} & 5.08\end{array}$ & 6.57 & 6.46 & 9.87 & 47.19 & 7.65 \\
\hline $\begin{array}{l}\text { LAWC22 } \\
\text { (AN-107) }\end{array}$ & 0 & $\begin{array}{cc}\mathrm{Li}_{2} \mathrm{O} & 2.51 \\
\mathrm{Na}_{2} \mathrm{O} & 14.40 \\
\mathrm{MgO} & 1.51 \\
\mathrm{~K}_{2} \mathrm{O} & 0.08 \\
\mathrm{CaO} & 5.11\end{array}$ & 5.42 & 6.07 & 10.05 & 46.60 & 8.04 \\
\hline $\begin{array}{c}\text { II-129 } \\
\text { (AP-101) }\end{array}$ & $\begin{array}{c}0.020 \\
5 \% \mathrm{Tc}^{4+} \\
+ \\
95 \% \mathrm{Tc}^{7+}\end{array}$ & $\begin{array}{cc}\mathrm{Na}_{2} \mathrm{O} & 19.49 \\
\mathrm{MgO} & 1.88 \\
\mathrm{~K}_{2} \mathrm{O} & 4.06 \\
\mathrm{CaO} & 1.86\end{array}$ & 6.65 & 5.89 & 8.69 & 40.25 & 7.18 \\
\hline $\begin{array}{l}\text { LAWA125 } \\
\text { (AP-101) }\end{array}$ & 0 & $\begin{array}{cc}\mathrm{Na}_{2} \mathrm{O} & 20.00 \\
\mathrm{MgO} & 1.44 \\
\mathrm{~K}_{2} \mathrm{O} & 4.21 \\
\mathrm{CaO} & 1.94\end{array}$ & 5.39 & 5.64 & 9.55 & 42.91 & 8.76 \\
\hline
\end{tabular}


Waste glasses containing larger amounts of $\mathrm{Tc}^{7+}$ ( $\geq 50 \mathrm{ppm}$ ), II-118, II-127, II-128, and II-129, have enhanced Raman intensity near $900 \mathrm{~cm}^{-1}$ in the VV spectrum with respect to the Tc-free equivalent glass (Figs. 10 and 11), similar to that observed for the I-283 standard glasses. The major Raman spectral features for Tc-containing and Tc-free glass pairs are similar. For II-129 glass (Figure 10), intensity enhancement is mostly centered near $900 \mathrm{~cm}^{-1}$ and continues as a low frequency shoulder near $830 \mathrm{~cm}^{-1}$. The Tc-free LAWA125 glass has larger Raman intensities near 630 and $990 \mathrm{~cm}^{-1}$ with respect to II-129 glass, which are likely due to higher sulfate content 48 at the particular point measured for LAWA125 glass. For II-128 glass (Figure 11), the spectrum has intensity enhancement that spans nearly $160 \mathrm{~cm}^{-1}$, which may be due to pertechnetate $v_{1}$ modes at different frequencies. II-128 glass has the highest $\mathrm{Tc}^{7+}$ concentration of all waste glasses investigated. Correspondingly, a barely discernable O-Tc-O bend mode near $320 \mathrm{~cm}^{-1}$ is seen, superimposed on the low frequency envelope due to de-localized borosilicate network modes (Figure 11); this feature is not observed in the spectra of the other waste glasses (Figure 10). Similar to II-13 glass, no Tc-dependent Raman features are observed for II-121 glass with respect to its Tc-free counterpart, LAWC22, because II-121 glass has the lowest Tc concentration of all samples investigated, with approximately $30 \mathrm{ppm}$ Tc of which $80 \%$ is $\mathrm{Tc}^{4+}$.

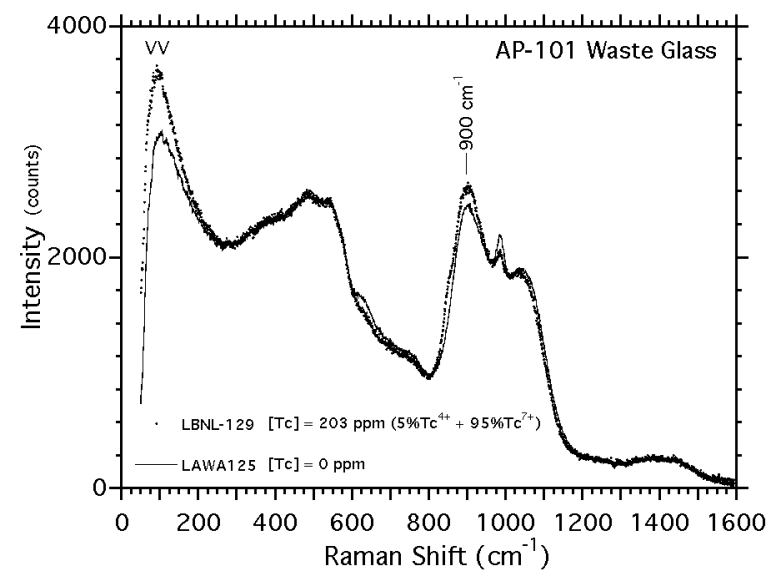

Figure 10. Parallel polarized Raman spectra of an AP-101 borosilicate waste glass containing $193 \mathrm{ppm} \mathrm{Tc}{ }^{7+}$ (II-129) and of the corresponding Tc-free LAWA125 borosilicate base glass. The pertechnetate dependent feature is indicated. 


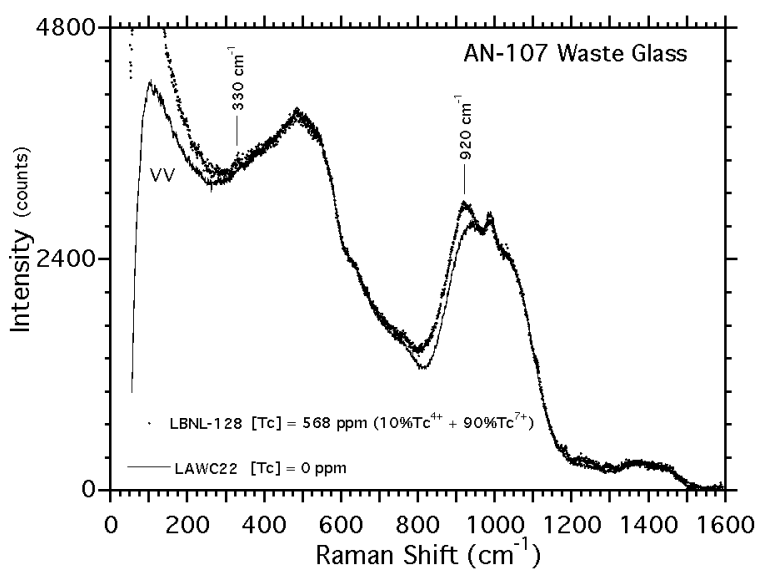

Figure 11. Parallel polarized Raman spectra of an AN-107 borosilicate waste glass containing 511 ppm $\mathrm{Tc}^{7+}$ (II-128) and of the corresponding Tc-free LAWC22 borosilicate base glass. Pertechnetate dependent features are indicated.

Pertechnetate Mode Spectral Trends. The relative intensity of the pertechnetate Tc-O stretch mode peak near $905 \mathrm{~cm}^{-1}$ increases as the $\mathrm{Tc}^{7+}$ concentration increases. This is seen by comparing the spectra of the $10,000 \mathrm{ppm}$ pertechnetate solution, the $1580 \mathrm{ppm}$ pertechnetate I-283 standard glass, the 511 ppm pertechnetate II-128 waste glass, and the $193 \mathrm{ppm}$ pertechnetate II-129 waste glass (Figs. 7, 8, 10, and 11). Unfortunately, quantitatively determining pertechnetate concentrations from these Raman intensities may not be simple for the waste glasses presented here because major element chemistry differences between Tc-containing and Tc-free glasses may also contribute to Raman intensity variations near $900 \mathrm{~cm}^{-1}$.

The frequency of the pertechnetate $v_{1}$ mode may be useful for determining the average cation type surrounding pertechnetate tetrahedra in a borosilicate waste glass. What appear to be different $v_{1}$ frequencies, $900 \mathrm{~cm}^{-1}$ for II-129 glass and $920 \mathrm{~cm}^{-1}$ for II-128 glass (Figs. 10 and 11), may indicate different network-modifying cation types around $\mathrm{TcO}_{4}{ }^{-}$within these two different waste glasses. Sulfate tetrahedra $v_{1}$ mode frequency relationships were observed for network modifying cation types in borosilicate glasses (Figure $8 \mathrm{c}$ in ${ }^{48}$ ), where increasing average charge density of the network modifying cations leads to increasing frequency of the S-O stretch $v_{1}$ mode. The same relationship appears to apply for the pertechnetate $v_{1}$ mode in crystals, where the mode frequency increases as the charge density of the surrounding cation increases for $\mathrm{AgTcO}_{4}, \mathrm{NH}_{4} \mathrm{TcO}_{4}$, and $\mathrm{KTcO}_{4}{ }^{46}$ If this relationship applies to pertechnetate tetrahedra surrounded by network-modifying cations in borosilicate waste glasses, then one would expect higher charge density network-modifying cations in II-128 glass than in II-129 glass. This is the case (see Table 8), where II-128 has larger concentrations of the higher charge-density networkmodifying $\mathrm{Ca}^{++}$and $\mathrm{Li}^{+}$, and where II-129 glass has larger concentrations of the lower chargedensity network-modifying $\mathrm{Na}^{+}$and $\mathrm{K}^{+}$.

The pertechnetate $v_{1}$ mode peak can have a different shape in the VV spectrum from one glass sample to another. For the pertechnetate solution and I-283 glass standards, the $v_{1}$ mode peak is relatively symmetrical and centered around one frequency (Figs. 7 and 8). However, this mode 
appears to be distributed over different frequency ranges for the two waste glass types (Figs. 10 and 11), which may indicate that pertechnetate tetrahedra in these samples are situated within different varieties of bonding environments. The 930 to $820 \mathrm{~cm}^{-1}$ Raman intensity enhancement for II-129 waste glass (Figure 10) is mostly centered near the $900 \mathrm{~cm}^{-1}$ peak but extends to lower frequencies. The 950 to $790 \mathrm{~cm}^{-1}$ Raman intensity enhancement for II-128 glass (Figure 11) has most of its area near 920 and $800 \mathrm{~cm}^{-1}$, with intensity enhancement between these frequencies. By comparing glass compositions (Table 8), the wider frequency range of the Raman intensity enhancement for II-128 glass versus II-129 glass would indicate a wider range of bonding environments for pertechnetate tetrahedra. If pertechnetate tetrahedra are surrounded by network modifying alkaline and alkaline earth cations, then this wider range of pertechnetate bonding environments appears to be reflected in the network modifying cation compositions, where II-128 glass has a broader variety of these cations ( $\mathrm{Li}$ to $\mathrm{Ca}$ ) than II-129 glass ( $\mathrm{Na}$ to $\mathrm{Ca}$ ). Other major element chemistry differences between the Tc-containing and Tc-free glasses may also contribute to the Raman intensity differences near $900 \mathrm{~cm}^{-1}$, which could be mistakenly associated with the $v_{1}$ pertechnetate mode.

The Raman intensity findings above indicate the potential for quantitatively determining pertechnetate concentrations for an unknown borosilicate glass sample by measuring areas under the Tc-dependent features. To do this accurately, minimizing composition differences between Tc-containing and Tc-free glass pairs is essential, so that direct spectral subtraction would ideally eliminate all Raman intensities except for that from any Tc-dependent modes.

\section{Conclusions}

This study shows that Raman spectroscopy is capable of detecting pertechnetate within various borosilicate waste glass formulations, even at quite low concentrations. The Raman spectral comparisons between chemically similar Tc-containing and Tc-free borosilicate glasses indicate Tc-dependent features near 320 and $910 \mathrm{~cm}^{-1}$ that are due to vibrational modes internal to pertechnetate tetrahedra. The intensity dependence of pertechnetate modes near $910 \mathrm{~cm}^{-1}$ with regard to pertechnetate concentration indicates a Raman detection limit near 50 ppm in borosilicate glass; the presence of the much weaker $320 \mathrm{~cm}^{-1}$ Tc-dependent mode may indicate pertechnetate concentrations greater than 500 ppm in borosilicate glass. The Raman evidence of pertechnetate modes observed for a pertechnetate solution, for pertechnetate crystals, and for pertechnetate-containing borosilicate glasses, indicates that most $\mathrm{TcO}_{4}{ }^{-}$tetrahedra in borosilicate waste glasses are probably surrounded by network modifying alkaline and alkaline earth cations; however, this evidence cannot completely exclude the possibility of some $\mathrm{TcO}_{4}{ }^{-}$tetrahedra bonded to the borosilicate network. The frequency of the $v_{1}$ pertechnetate mode may provide information about the type of cations surrounding $\mathrm{TcO}_{4}{ }^{-}$tetrahedra within a sample of interest. On the other hand, no Tc-dependent Raman features were observed for six-coordinated $\mathrm{Tc}^{4+}$ species in borosilicate glasses. 


\section{Behavior of technetium and rhenium during borosilicate waste glass vapor hydration tests}

\section{Introduction}

One of the most difficult problems associated with the use of nuclear power and the disposition of nuclear wastes from fuel reprocessing is the long-term immobilization of the radionuclides produced during fission, such as technetium $\left({ }^{99} \mathrm{Tc}\right)$. Tc is a $\beta$-emitter with a half-life of $2.13 \times 10^{5}$ years. The thermodynamically stable form of Tc in aerobic environments is highly mobile pertechnetate (Tc(VII) within $\mathrm{TcO}_{4}{ }^{-}$tetrahedra). ${ }^{51,52}$ The long half-life and high mobility of pertechnetate frequently make it one of the most significant environmental risk contributors in the performance assessment of nuclear waste disposal repositories. Currently, the chosen method of treatment for the most highly radioactive nuclear wastes is vitrification to produce a durable glass matrix. It is known from the geologic record that natural glasses of appropriate compositions have survived for millions of years in the environment. ${ }^{53}$ Projection of the fate of waste glasses in the environment, which necessarily have somewhat different compositions from natural glasses, requires an understanding of the processes and mechanisms by which they alter on exposure to the prevailing environmental conditions; reaction with water is crucial in this regard. Since the preferred glass compositions have inherently low rates of alteration, a variety of accelerated test methods have been developed wherein other test variables (such as temperature or surface area to volume ratio) are employed to bring about a greater extent of reaction in a shorter time. Such tests have proved useful in elucidating reaction mechanisms and in the downselection of glass compositions. One such test method, which is the subject of this study, is the Vapor Hydration Test (VHT).

The VHT employs hydrothermal conditions to accelerate the rate of glass alteration. In the VHT, a glass coupon is exposed to a water-saturated atmosphere in a sealed pressure bomb at elevated temperatures for specified time intervals. At the end of the test, the coupon is sectioned and analyzed to determine the thickness of the reacted layer, which gives a measure of the rate of reaction, and the types and compositions of the alteration phases that are produced. ${ }^{54-58}$ Previous work has shown that water diffuses into the glass ahead of the alteration zone and that alteration phases can develop either in place of the native glass or growing out from the coupon surface. ${ }^{54-}$ ${ }^{58}$ However, to the best of our knowledge, Tc behavior is unknown with regard to mobility and speciation within a borosilicate waste-form under VHT conditions. In view of the practical importance of rhenium, which is commonly used as a non-radioactive surrogate for Tc, tests were also performed on two Re-containing waste glasses to allow comparisons with the behavior of Tc.

The speciation and local coordination environments of Tc and Re, in the original glasses and the corresponding VHT samples, were determined using X-ray absorption spectroscopy (XAS). As shown earlier, XAS can distinguish $\mathrm{Tc}(\mathrm{IV}) \mathrm{O}_{6}$ octahedra from $\mathrm{Tc}(\mathrm{VII}) \mathrm{O}_{4}$ tetrahedra in borosilicate waste glasses and other materials. ${ }^{44,45,59,60}$ Tc K-edge X-ray absorption near edge structure (XANES) for $\mathrm{Tc}(\mathrm{IV})$ and $\mathrm{Tc}(\mathrm{VII})$ are distinctive. ${ }^{44,45,60}$ The structural parameters extracted from the extended X-ray absorption fine structure (EXAFS) data can also be used to distinguish pertechnetate tetrahedra, which have Tc-O distances near $1.72 \AA$, from Tc(IV) octahedra, which have Tc-O distances near $1.98 \AA$. Recent studies have also shown that $\mathrm{Re}_{\mathrm{II}}$ 
XANES data can be used to distinguish Re(VII) from more reduced species in borosilicate waste glasses. $^{45}$

\section{Experimental Section}

Sample Preparation. Four borosilicate glasses were investigated. Two Tc-containing glasses, II-118 and II-121, were synthesized in Pt/Au crucibles in air within a tube furnace at $1150{ }^{\circ} \mathrm{C}$; both samples contain no $\mathrm{ZrO}_{2}$ to avoid large X-ray fluorescence background intensity in the Tc K-edge XAS data. Two Re-waste glasses, WVT-G-126B and WVT-G-128B, were produced in test runs on a continuously-fed ceramic-lined Joule-heated melter, where the $\sim 110 \mathrm{~kg}$ melt pool was maintained at $1150{ }^{\circ} \mathrm{C}$ and agitated by an air bubbler. ${ }^{23}$ Reagent-grade chemical components were used for glass synthesis. Tc concentrations in the original glasses were determined by liquid scintillation measurements on solutions generated by microwave-assisted $\mathrm{HNO}_{3} / \mathrm{HF}$ dissolution of the glass samples. All glasses were determined to be crystal-free by X-ray diffraction (XRD), except for a few isolated Pt inclusions in the Tc-containing glasses.

Individual wafers were cut from the two Tc-containing glasses and the two Re-containing melter glasses for the VHT experiments. Each wafer was suspended above a small amount of water in a sealed stainless steel VHT pressure bomb that was flushed with $\mathrm{Ar}$, and then held at $238{ }^{\circ} \mathrm{C}$ for 24.9 days. At the end of the VHT, optical inspection found that the II-118 and II-121 VHT samples were reacted throughout, while the WVT-G-126B and WVT-G-128B VHT samples were $60-70 \%$ reacted. It should be noted that the difference in the degree of alteration is due to $\mathrm{ZrO}_{2}$ content variations in these glasses and not the differences between Tc and Re. XRD indicates analcime $\left(\mathrm{NaAlSi}_{2} \mathrm{O}_{6} \cdot \mathrm{H}_{2} \mathrm{O}\right)$, and possibly, Zn-silicate crystalline phases in the Tc-containing VHT altered samples. Additional sample preparation and VHT details are in the Supporting Materials.

SEM Measurements. Concentrations of Tc and Re in the original glasses and in the corroded VHT coupon cross-sections were determined by wavelength dispersive spectroscopic (WDS) analysis. All elements present at $1 \mathrm{wt}$.\% or greater (as oxides) were analyzed to provide the basis for matrix corrections, except $\mathrm{H}, \mathrm{Li}$, and $\mathrm{O}$, with the last being evaluated by stoichiometry. The starting glasses were used as standards for all elements except Tc and Re. For Tc, a specially prepared specimen containing $\mathrm{Na}$, Tc, Si, and $\mathrm{O}$ was used, whereas for $\mathrm{Re}, \mathrm{ReO}_{3}$ was used.

XAS Data Collection. Tc K-edge and Re $\mathrm{L}_{\mathrm{II}}$-edge XAS data were collected in fluorescence mode at Stanford Synchrotron Radiation Laboratory Beam Lines 4-1 and 11-2. Due to the relatively low Tc concentrations in the original Tc-containing glasses, only Tc XANES data could be collected and analyzed. The X-ray fluorescence signal was significantly improved for both Tc-containing altered VHT wafers, such that XANES as well as EXAFS data were collected for these samples. This signal improvement for the Tc-containing VHT wafers indicates significant Tc enrichment at the VHT wafer surface compared with the Tc distribution in the original glass, a result confirmed by SEM analysis. No improvement in the XAS data was observed for the Re-containing VHT samples compared with the data for the original glasses.

XAS Data Analysis. The X-ray absorption spectra were processed using standard pre-edge background subtraction and edge-step normalization procedures. ${ }^{61}$ Each spectrum was calibrated to the inflection point of the K-edge peak for $\mathrm{TcO}_{4}{ }^{-}$at $21,044 \mathrm{eV}$ or the $\mathrm{L}_{\mathrm{II}}$-edge spectrum of $\mathrm{Re}$ 
metal at 11,959 eV. Energy values in eV were converted to $\mathrm{k}\left(\AA^{-1}\right)$, where after background subtraction, the resulting $\chi(\mathrm{k})$ data were $\mathrm{k}^{3}$-weighted and then Fourier transformed to produce the partial radial distribution functions (RDFs). XAS data for crystalline $\mathrm{TcO}_{2}$ and amorphous $\mathrm{TcO}_{2} \bullet \mathrm{xH}_{2} \mathrm{O}\left(a-\mathrm{TcO}_{2} \bullet \mathrm{xH}_{2} \mathrm{O}\right.$, where $\left.\mathrm{x} \sim 1.6\right)$ were used for comparisons with the Tc-containing VHT sample data, and were presented. ${ }^{44,59}$ Tc-O and Tc-Tc correlations determined for crystalline $\mathrm{TcO}_{2}$ and $a-\mathrm{TcO}_{2} \bullet \mathrm{xH}_{2} \mathrm{O}$ were used to label the major RDF features for these samples.

FEFF 7.02 computer code was used to calculate important Tc-O and Tc-Tc correlations in crystalline $\mathrm{TcO}_{2}{ }^{62}$ Due to the complex Tc environment in crystalline $\mathrm{TcO}_{2}$, with five different Tc-O nearest-neighbor distances (ranging from 1.96 to $2.06 \AA$ ) and nine different Tc-Tc distances (ranging from 2.29 to $3.67 \AA$ ), the data for this sample was not used as the reference for EXAFS fitting. ${ }^{59}$ Instead, the calculated Tc-O and Tc-Tc correlations were used by the fitting program, FEFFIT to fit the partial RDF for $a-\mathrm{TcO}_{2} \bullet \mathrm{xH}_{2} \mathrm{O}$, where the results were checked against those presented. ${ }^{26,44}$ FEFFIT determined $r$ (average bond distance), $n$ (coordination number), and $\sigma^{2}$ (Debye-Waller factor) for the major features in the partial RDFs for $a$ $\mathrm{TcO}_{2} \bullet \mathrm{xH}_{2} \mathrm{O}$ and the two Tc-containing VHT samples (Table 9). FEFFIT varied $r, n$, and $\sigma^{2}$ for each atomic shell, while minimizing the r-factor, a goodness of fit parameter that is a sum-ofsquares measure of the fractional misfit scaled to the magnitude of the data (Table 9).

\section{Results and Discussion}

\section{VHT Treated Samples: Tc-Containing Waste Glasses}

SEM Observations. SEM-WDS analyses for Tc were made at several selected points within the original glass samples, where the Tc concentrations were 0.008 and 0.004 wt.\% for II-118 and II-121 glasses, respectively. SEM-WDS analyses of both VHT samples indicate Tc and Si occur together at the locations analyzed, which suggests that Tc is incorporated within silicates. The SEM findings indicate that it is unlikely that Tc within these samples is in $a-\mathrm{TcO}_{2} \bullet \mathrm{xH}_{2} \mathrm{O}$, unless particles, with diameters considerably less than $1 \mu \mathrm{m}$, of this phase are suspended within silicates.

SEM-WDS analyses on cross-sections of both VHT samples indicate Tc concentration variations as a function of distance from the surface (Figure 12). Tc concentrations at the II-118 VHT sample surface are enhanced by approximately 50\%, compared with that in the original glass (Figure 12). At depths of 25 to $125 \mu \mathrm{m}$ from the surface, Tc concentrations are similar to those in the original glass. However, beyond a depth of $150 \mu \mathrm{m}$, Tc appears to be completely depleted from the sample (statistically zero). Similar relationships are observed for Tc concentrations within the II-121 VHT sample. Near the surface, at depths up to $150 \mu \mathrm{m}$, Tc concentrations can be five times of that measured by SEM for the original II-121 glass. Between depths of 175 and $300 \mu \mathrm{m}$, Tc concentrations within this VHT sample are similar to those found for the original II-121 glass; at depths greater than $300 \mu \mathrm{m}$, Tc concentrations approach zero. 


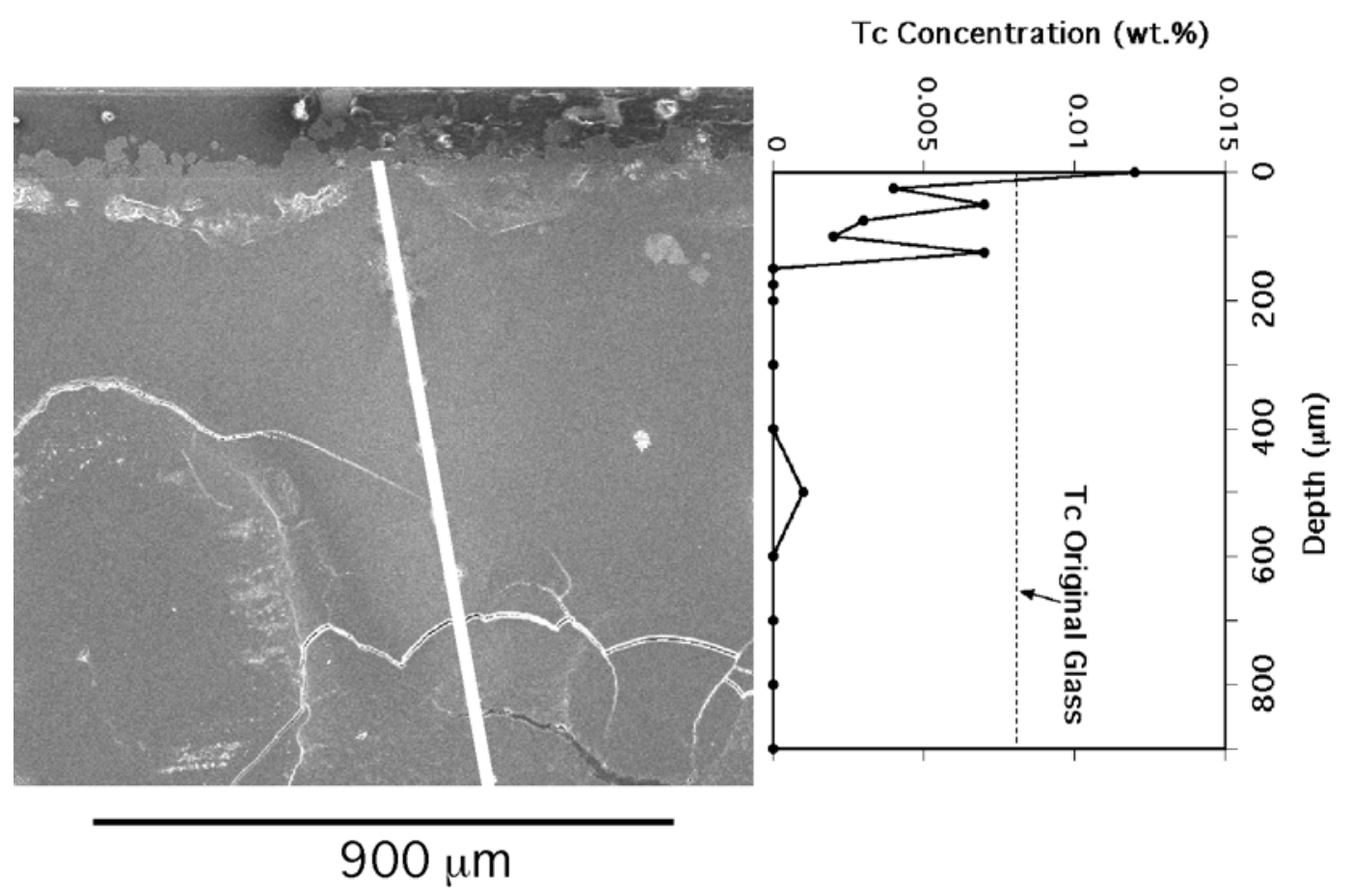

Figure 12. SEM-WDS Tc analyses for the II-118 VHT sample cross-section. The side plot indicates Tc concentration versus cross-section depth from the outer surface. The analysis profile is the white bar in the SEM micrograph.

SEM analyses for most major elements in both VHT samples indicate that concentrations remain relatively constant throughout the cross-section profiles. Exceptions are $\mathrm{Na}, \mathrm{Ca}$, and $\mathrm{Fe}$ for the II-118 VHT sample, and Ca for the II-121 VHT sample, where these elements show significant enrichment near the surface.

Both Tc-containing VHT samples were completely altered, such that none of the original glass remained. The SEM images for both samples indicate significant differences with regard to how each original glass was altered. The II-118 VHT sample shows more homogeneous alteration textures, where ill-defined bands of various phases can be seen just under the surface and near a depth of $900 \mu \mathrm{m}$ (Figure 12). The II-121 VHT sample has a more complex assemblage of alteration phases and phase intergrowth textures throughout, with more distinct bands.

XANES Results. Tc K-edges for the two samples show significant changes before and after the VHT (Figure 13). XANES for the VHT samples are shifted to lower energies and show no evidence of the 21,045 eV pertechnetate edge feature (Figure 14 bottom) compared with the XANES for II-118 and II-121 glasses. The XANES for the $100 \%$ Tc(VII) standard glass (I-283) and the $100 \% \mathrm{Tc}$ (IV) standard glass (II-13) show significant edge shape differences as well as a $3.5 \mathrm{eV}$ edge energy shift (measured at half the edge-step) (Figure 14). ${ }^{45}$ Fitting the XANES data for the original glasses (Figure 13), using the spectra of the Tc(IV) and Tc(VII) glass standards, indicate $20 \%$ Tc(IV) + 80\% Tc(VII) for II-118 glass versus $80 \%$ Tc(IV) + 20\% Tc(VII) for II121 glass. $^{45}$ These changes indicate that any pertechnetate originally present in the II-118 and 
II-121 glasses has been reduced to Tc(IV) during VHT alteration. The data for both VHT samples are different from the spectrum for the $100 \%$ Tc(IV) II-13glass (Figure 14). The two peaks near 21,065 and 21,075 eV in both VHT sample spectra are similar to those observed for crystalline $\mathrm{TcO}_{2}$ and $a-\mathrm{TcO}_{2} \bullet \mathrm{xH}_{2} \mathrm{O}$ (Figure 14). ${ }^{44}$ The double peak feature for the II-121 VHT sample is clearly more resolved than that for the II-118 VHT sample, indicating structural differences around Tc. From the XANES evidence, the Tc environments in both VHT samples appear to be similar to those in crystalline $\mathrm{TcO}_{2}$ or $a-\mathrm{TcO}_{2} \bullet \mathrm{xH}_{2} \mathrm{O}$, where $\mathrm{Tc}(\mathrm{IV}) \mathrm{O}_{6}$ units link to create Tc-Tc second-nearest neighbors. 


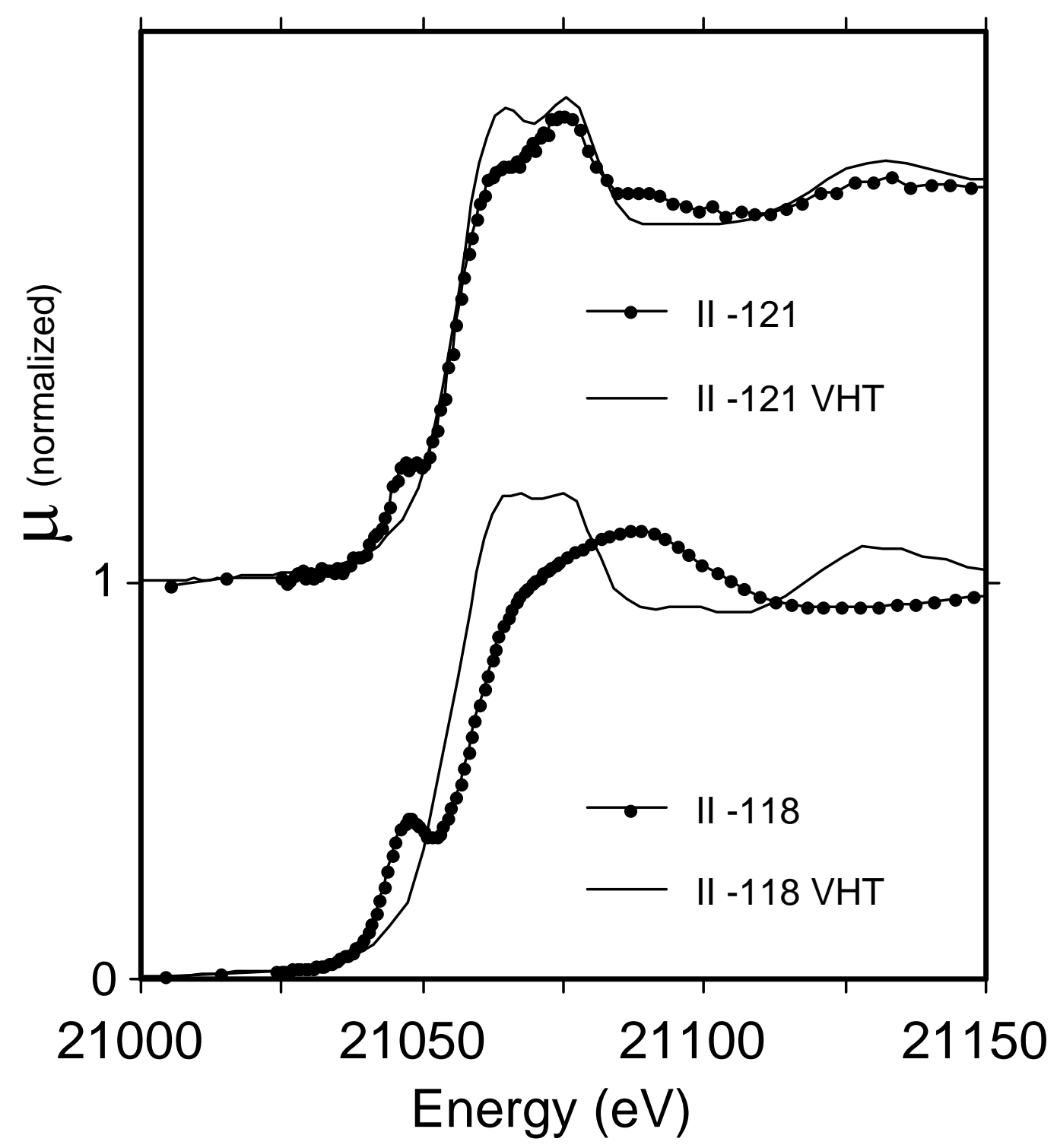

Figure 13: Tc K-edge XANES data for the II-118 and II-121 samples before and after VHT treatment. II-118 glass contains 20\%Tc(IV) $+80 \% \mathrm{Tc}(\mathrm{VII})$ and II-121 glass contains $80 \%$ Tc(IV) $+20 \%$ Tc(VII). ${ }^{45}$ Both corresponding VHT samples have $100 \%$ Tc(IV). 


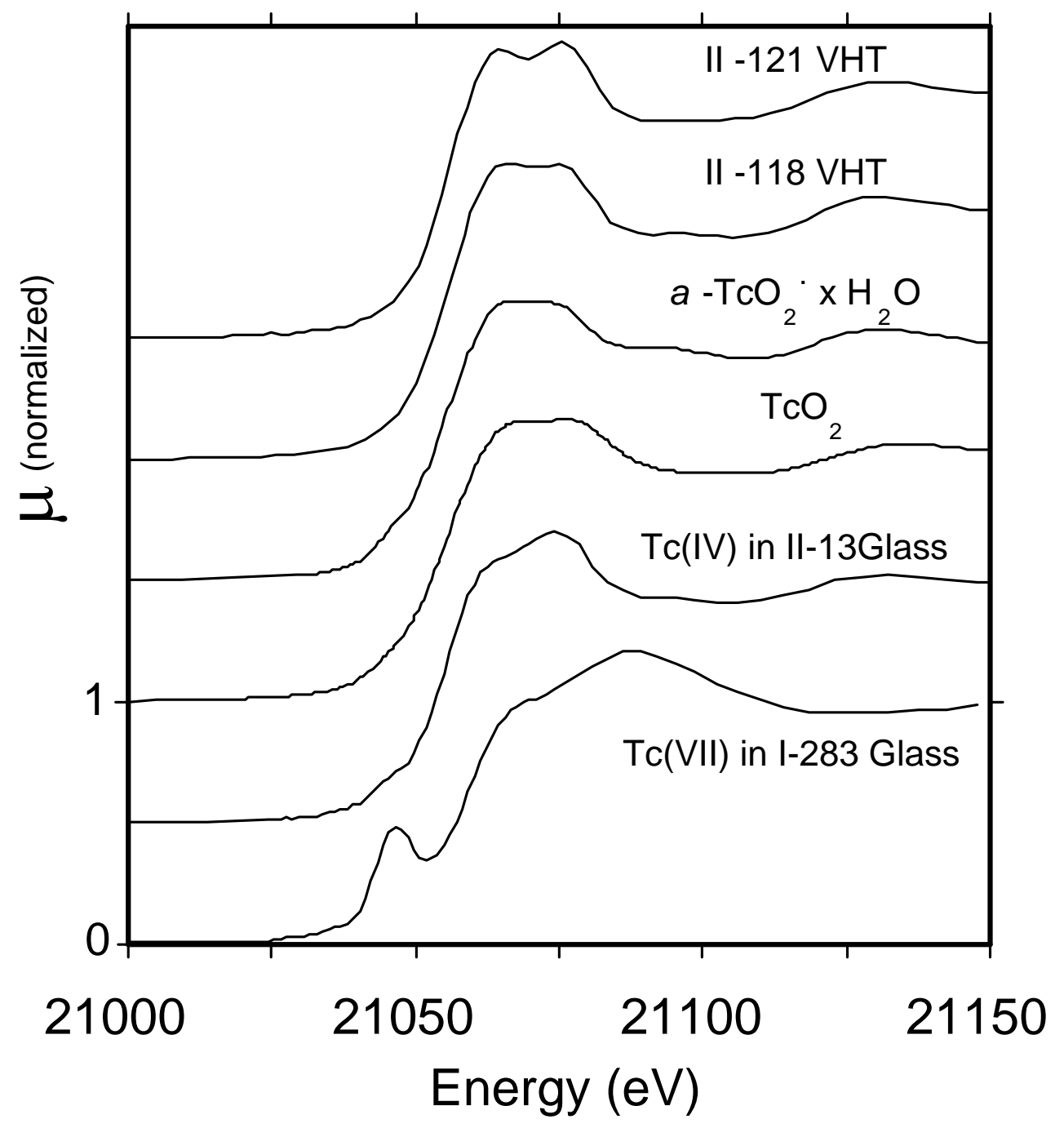

Figure 14: Tc XANES of the Tc(VII) in glass standard, crystalline and amorphous $\mathrm{Tc}(\mathrm{IV})$ standards, and the two Tc-containing VHT samples.

EXAFS Results. The $\mathrm{k}^{3} \chi(\mathrm{k})$ data for both VHT samples have larger oscillation amplitudes at $\mathrm{k}$ values under $8 \AA^{-1}$ than those observed for $a-\mathrm{TcO}_{2} \bullet \mathrm{xH}_{2} \mathrm{O}$, that are similar to those for crystalline $\mathrm{TcO}_{2}$ (Figure 15). At k-values greater than $8 \AA^{-1}$, the data for II-118 VHT and $a-\mathrm{TcO}_{2} \bullet \mathrm{xH}_{2} \mathrm{O}$ are similar, while the data for crystalline $\mathrm{TcO}_{2}$ is different from the other three samples. The data for $a-\mathrm{TcO}_{2} \cdot \mathrm{xH}_{2} \mathrm{O}$ and the II-118 VHT sample show at least two different frequency components, whereas one dominant frequency component is observed for the II-121 VHT sample. 


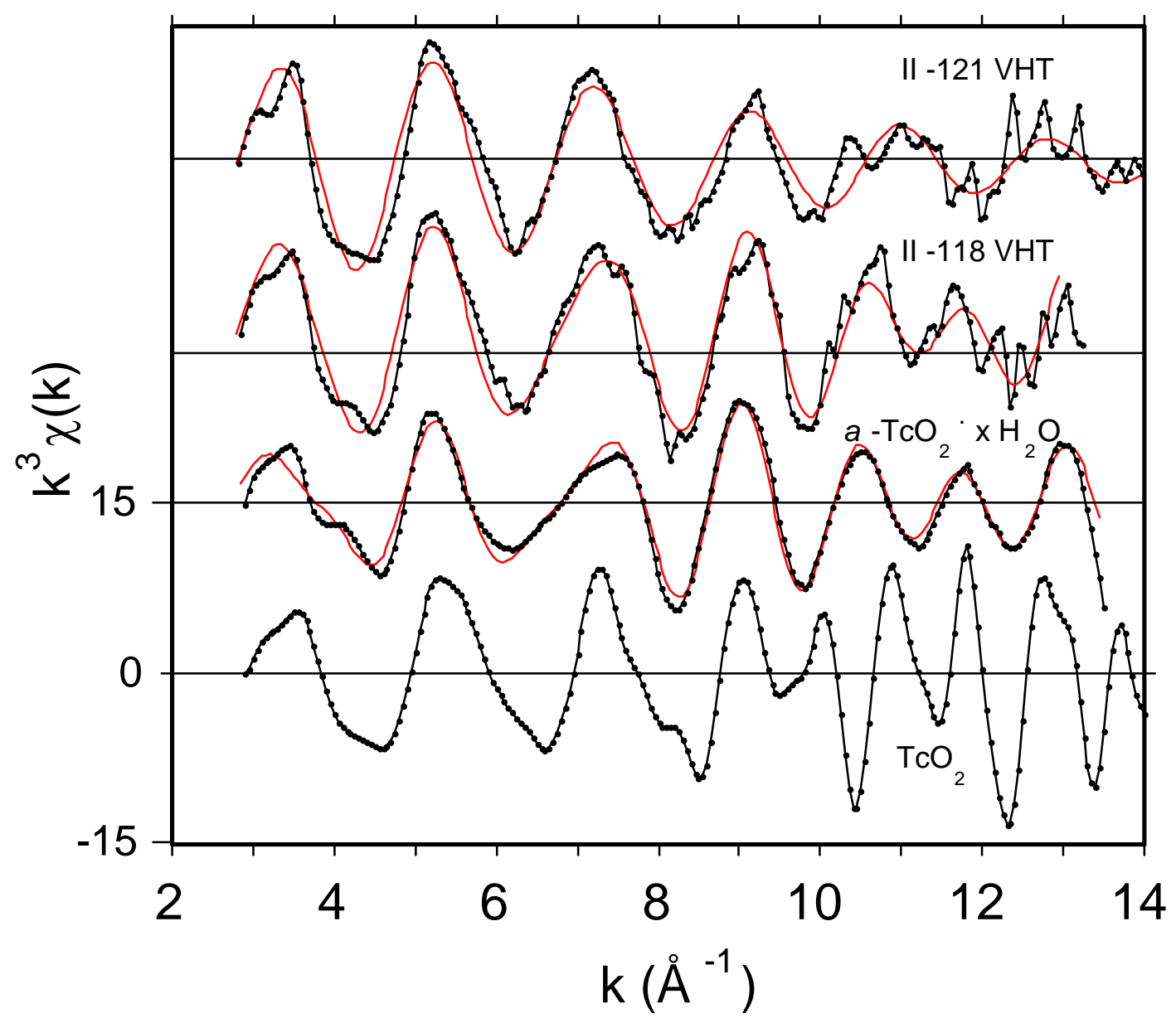

Figure 15: Tc EXAFS data (line and points) and analysis fit (red line) for crystalline $\mathrm{TcO}_{2}$, $a-\mathrm{TcO}_{2} \bullet \mathrm{XH}_{2} \mathrm{O}$ and the two Tc VHT samples.

The partial RDFs clearly indicate structural differences among the four samples (Figure 16). The two VHT samples show similar first shell peak amplitudes to that for crystalline $\mathrm{TcO}_{2}$; the first shell peak amplitude for $a-\mathrm{TcO}_{2} \bullet \mathrm{xH}_{2} \mathrm{O}$ is noticeably weaker than that for the other three samples. The RDF for the II-118 VHT sample has a second shell peak near 2.4 $\AA$, similar to the Tc-Tc peak for $a-\mathrm{TcO}_{2} \bullet \mathrm{xH}_{2} \mathrm{O}$. The RDF for the II-121 VHT sample has a nearest-neighbor peak near $1.7 \AA$. The RDF for $\mathrm{TcO}_{2}$ indicates Tc-Tc correlation peaks at $r$ greater than $2 \AA$ that are distinctly different from the other three samples.

The analysis of the $a-\mathrm{TcO}_{2} \bullet \mathrm{xH}_{2} \mathrm{O}$ data reproduced results obtained for this phase (Table 9). ${ }^{44}$ The fitting results indicate that $\mathrm{Tc}$ is coordinated by six oxygen atoms in a distorted octahedral arrangement: four equatorial oxygens at an average $2.01 \AA$ Tc-O distance and two apical 
oxygens (each associated with $\mathrm{H}_{2} \mathrm{O}$ ) at $2.49 \AA$ from Tc. Each Tc has two Tc second-nearest neighbors at $2.58 \AA$.

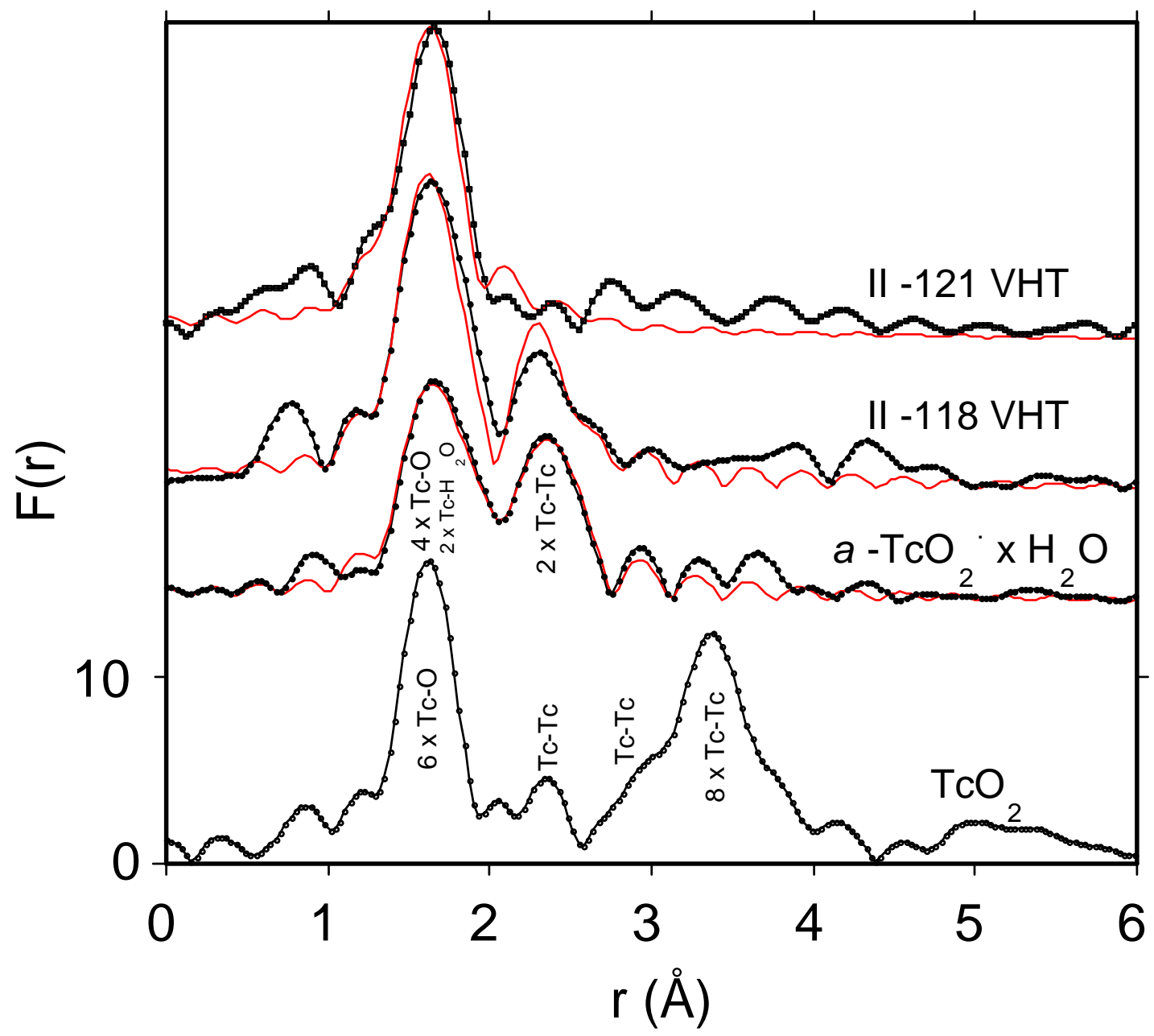

Figure 16: Tc partial RDFs (black line and points) and analysis fit (red line) for crystalline $\mathrm{TcO}_{2}$, $a-\mathrm{TcO}_{2} \bullet \mathrm{xH}_{2} \mathrm{O}$ and the two Tc VHT samples. Important pair correlations for $\mathrm{TcO}_{2}$ and $a$ $\mathrm{TcO}_{2} \bullet \mathrm{XH}_{2} \mathrm{O}$ are indicated (12). 
Table 9: Tc EXAFS Tc-O and Tc-Tc nearest-neighbor fitting results for a- $\mathrm{TcO}_{2} \bullet \mathrm{xH}_{2} \mathrm{O}$ and the two VHT samples ${ }^{\mathrm{a}}$. Uncertainties are in parentheses.

\begin{tabular}{|c|c|c|c|c|c|}
\hline Sample & r-factor ${ }^{b}$ & Correlation & $r(\AA)$ & $n$ (atoms) & $\sigma^{2}\left(\AA^{2}\right)$ \\
\hline \multirow[t]{6}{*}{$a-\mathrm{TcO}_{2} \cdot \mathrm{xH}_{2} \mathrm{O}$} & 0.007 & Tc-O: this study & $\begin{array}{c}2.01 \\
(0.01)\end{array}$ & $4.0(1.0)$ & $\begin{array}{r}0.0033 \\
(0.0022)\end{array}$ \\
\hline & & Tc-O: ${ }^{44}$ & 2.02 & 3.9 & 0.0022 \\
\hline & & Tc-O: this study & $\begin{array}{c}2.49 \\
(0.07)\end{array}$ & $1.4(0.3)$ & $\begin{array}{c}0.0065 \\
(0.0119)\end{array}$ \\
\hline & & Tc-O: ${ }^{44}$ & 2.47 & 1.4 & 0.0050 \\
\hline & & Tc-Tc: this study & $\begin{array}{c}2.57 \\
(0.01)\end{array}$ & $2.1(1.1)$ & $\begin{array}{c}0.0043 \\
(0.0025)\end{array}$ \\
\hline & & Tc-Tc: ${ }^{44}$ & 2.57 & 1.7 & 0.0029 \\
\hline \multirow[t]{2}{*}{ II-118 VHT } & 0.019 & Tc-O & $\begin{array}{c}2.00 \\
(0.01)\end{array}$ & $5.8(0.8)$ & $\begin{array}{r}0.0037 \\
(0.0013)\end{array}$ \\
\hline & & Tc-Tc & $\begin{array}{c}2.56 \\
(0.01)\end{array}$ & $1.0(0.2)$ & $\begin{array}{r}0.0015 \\
(0.0007)\end{array}$ \\
\hline II-121 VHT & 0.021 & Tc-O & $\begin{array}{c}2.00 \\
(0.01)\end{array}$ & $6.2(0.9)$ & $\begin{array}{c}0.0047 \\
(0.0014)\end{array}$ \\
\hline
\end{tabular}

a) All fits used: $\mathrm{s}_{0}^{2}=0.98$ and $\mathrm{E}_{0}=21,029.7 \mathrm{eV}$.

b) $\mathrm{r}$-factor $=\left(\sum\left(\mathrm{y}_{\mathrm{i}}(\text { data })-\mathrm{y}_{\mathrm{i}}(\text { fit })\right)^{2} / \sum\left(\mathrm{y}_{\mathrm{i}}(\text { data })\right)^{2}\right)^{1 / 2}$.

The EXAFS fitting routines for the VHT samples used a model based on the number of major RDF peaks for each sample: two shells were fit (Tc-O and Tc-Tc) to the II-118 data, while one shell was fit (Tc-O) to the II-121 data (Table 9). The second nearest-neighbor RDF peak in the II-118 VHT data could also be due to other cations than Tc in the original glass, such as Fe and Ti. Tc(IV) has a similar ionic radius to Fe(III) and Ti(IV) and has been known to substitute for Ti(IV) in titanium compounds. ${ }^{63}$ Therefore, two other fitting routines were applied to the II-118 VHT data, where the Tc-Tc path in the original model was replaced by Tc-Fe and then Tc-Ti. Both models poorly fit the experimental second-shell partial RDF peak, where $n$ or $\sigma^{2}$ refined to negative values. Therefore, the short $2.56 \AA$ cation-cation second nearest-neighbor distance is best described by Tc-Tc, which is observed in both $a-\mathrm{TcO}_{2} \bullet \mathrm{XH}_{2} \mathrm{O}$ and crystalline $\mathrm{TcO}_{2}(11,12) .{ }^{44}$,

The initial fits for the II-118 VHT sample did not completely describe the RDF amplitudes between 1.5 and $2.5 \AA$ (Figure 16). Another model was used, which added a Tc-O correlation, similar to that used for the water molecules coordinating with Tc in $a-\mathrm{TcO}_{2} \bullet \mathrm{xH}_{2} \mathrm{O}$; this model marginally improved the fit. This three-shell fit suggests that $\mathrm{H}_{2} \mathrm{O}$ may coordinate with some of the Tc atoms at distances near $2.45 \AA$. 
The fitting results for both VHT samples (Table 9) are consistent with local environments characteristic of Tc(IV), which support the XANES findings. The Tc environments in the VHT samples are considerably different from pertechnetate environments. ${ }^{45,60}$ The EXAFS data and fitting results also show that the Tc-O nearest-neighbor environments in the VHT samples are different from that in $a-\mathrm{TcO}_{2} \bullet \mathrm{xH}_{2} \mathrm{O}$. Larger nearest-neighbor peak amplitudes for the two VHT samples (Figure 16) correlate with the larger nearest-neighbor coordination numbers, and indicate somewhat regular $\mathrm{TcO}_{6}$ octahedra. Tc in the II-118 VHT sample could be within $\mathrm{Tc}_{2} \mathrm{O}_{10}$ dimers, where two $\mathrm{TcO}_{6}$ units share two oxygen atoms, similar to the proposed environment between two $\mathrm{TcO}_{6}$ units in solutions and other compounds. ${ }^{44,64}$ Tc in the II-121 VHT sample is also within somewhat regular $\mathrm{TcO}_{6}$ octahedra that appear to be isolated from each other.

\section{VHT Treated Samples: Re-Containing Melter Glasses}

SEM Observations. SEM investigations of the cross-sections of both Re-containing VHT samples indicate $\mathrm{Re}_{2} \mathrm{O}_{7}$ concentration profiles (Figure 17) that are distinctly different from those measured for the Tc-containing VHT samples (Figure 12). Both Re-containing VHT samples were not completely altered and portions of the original glass were found near the center of each sample. $\mathrm{Re}_{2} \mathrm{O}_{7}$ concentrations near the WVT-G-128B VHT sample surface are near zero, where some concentration enhancement was observed for both samples between 20 and $100 \mu \mathrm{m}$ depths. At depths greater than $375 \mu \mathrm{m}$, concentrations increase toward the unaltered glass (700 $\mu \mathrm{m}$ depth in Figure 17) to approach the original glass concentration. 

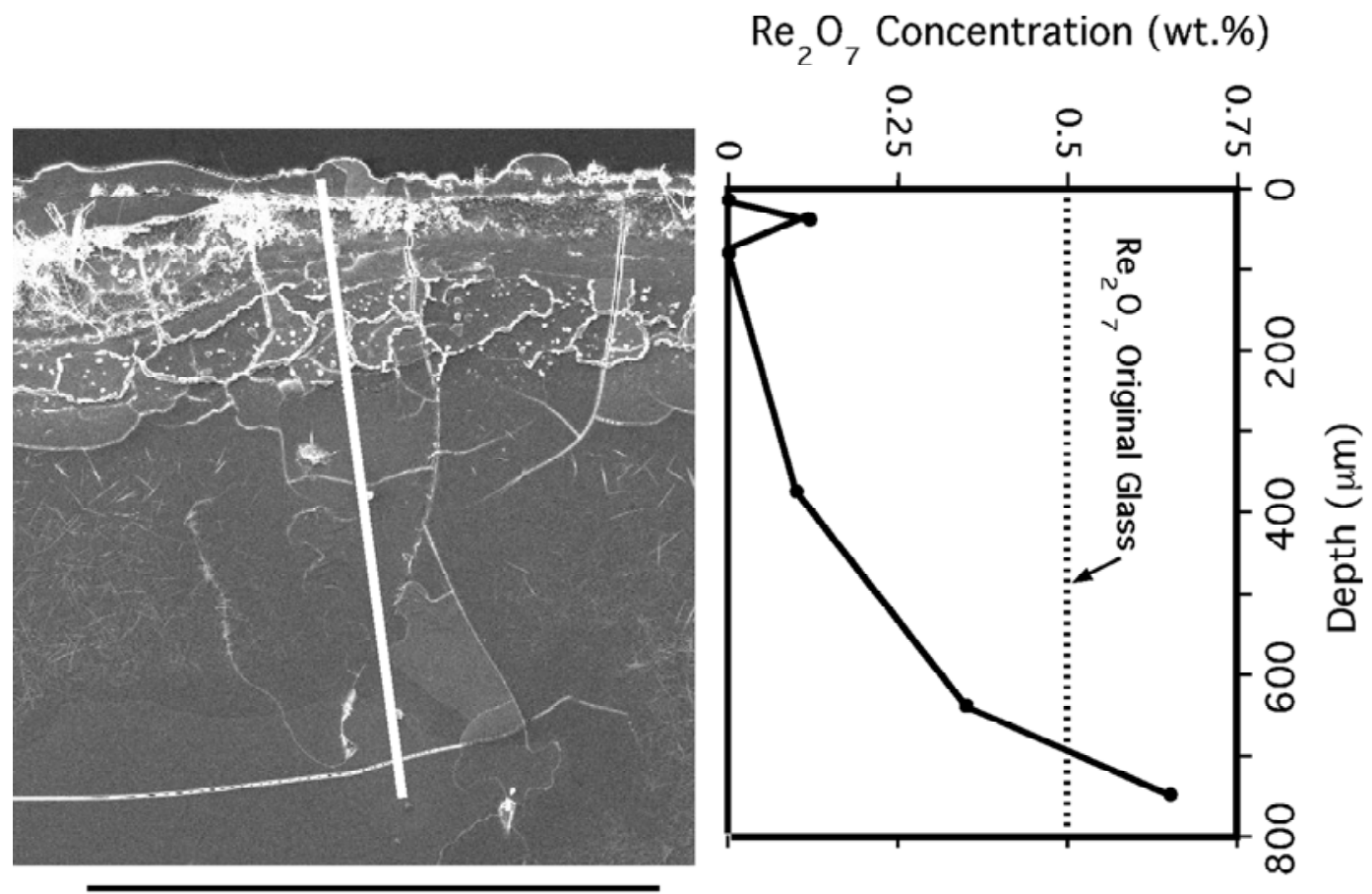

$700 \mu \mathrm{m}$

Figure 17: SEM-WDS $\mathrm{Re}_{2} \mathrm{O}_{7}$ analyses for the WVT-G-128B VHT sample cross-section. The analysis profile is the white bar in the SEM micrograph.

XAS Results. The two Re-containing melter glasses used in the VHT tests, have $100 \%$ of all Re as perrhenate in the original glasses, as shown by XANES and EXAFS. ${ }^{45}$ XANES data for both VHT altered samples also indicate perrhenate as the sole Re species (Figure 18). XANES data for both glasses and their corresponding VHT samples are nearly identical to those for $\mathrm{NH}_{4} \mathrm{ReO}_{4}{ }^{45}$ 


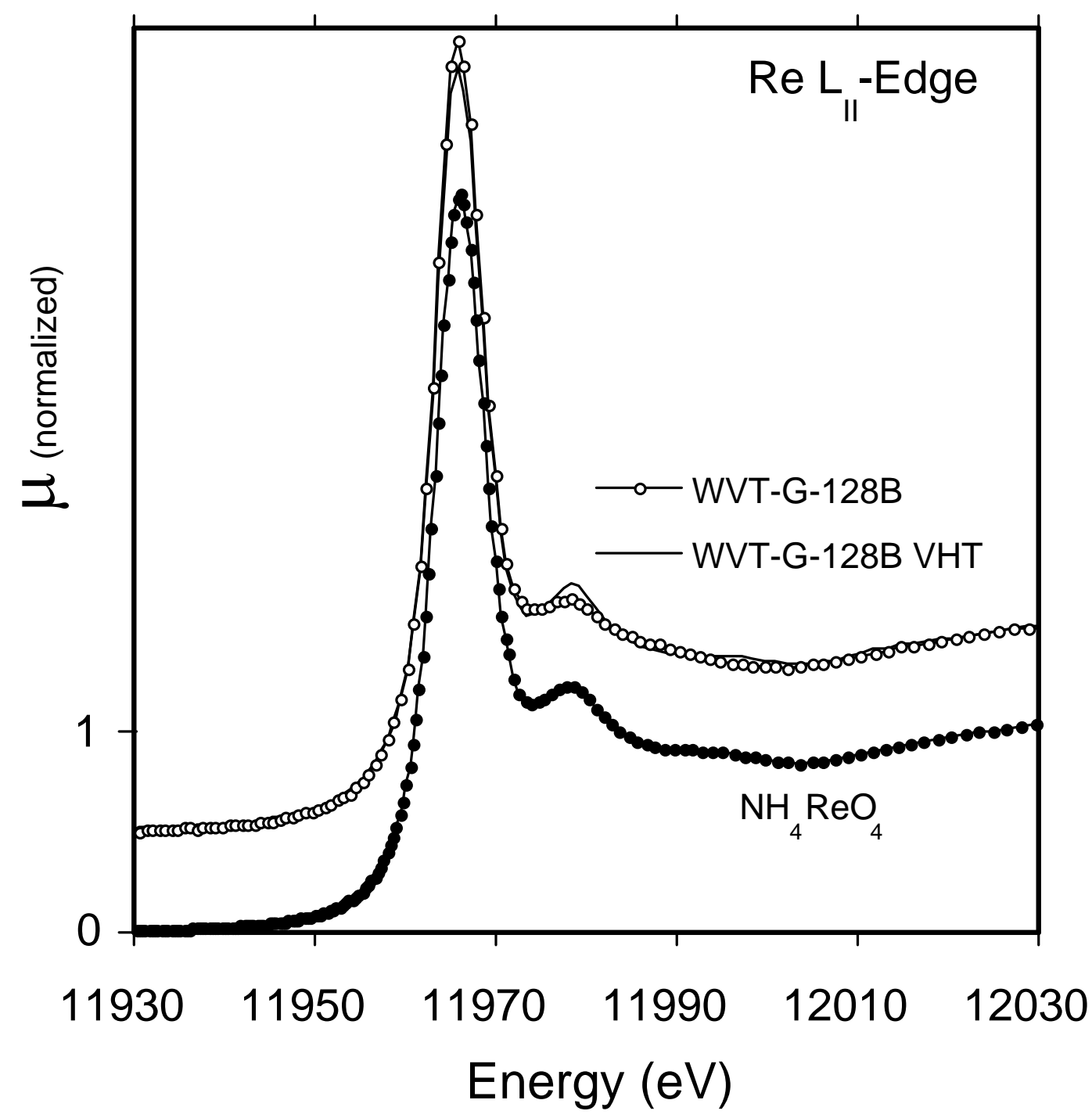

Figure 18. Re $\mathrm{L}_{\mathrm{II}}$-edge XANES data for $\mathrm{NH}_{4} \mathrm{ReO}_{4}$ as well as the melter glass WVT-G-128B before and after VHT treatment (offset for clarity). The spectra indicate $100 \%$ perrhenate $(\operatorname{Re}(\mathrm{VII}))$ in both samples.

Possible Tc Reduction Mechanism. The cause of the Tc reduction in the VHT environment is not well understood. However, earlier observations about Tc behavior in environments similar to that within the VHT vessel may provide some insights. Tc release was observed from glass powder in water within a heated stainless steel vessel, where a sudden drop of the Tc concentration in the glass was seen after 560 days; this drop was attributed to the formation of poorly soluble $\mathrm{Tc}(\mathrm{IV}){ }^{65}$ Similar results were also obtained within depleted oxygen environments, where $\mathrm{Zn}$-amalgam was used to deliberately scavenge oxygen. ${ }^{13}$ In other studies, Tc was soluble in air at room temperature, in systems containing water, glass, Tc(VII), stainless 
steel, and $\mathrm{UO}_{2}$; Tc was found to be insoluble under reducing conditions created by the addition of either metallic or ferrous iron. ${ }^{66}$

The likely explanation for the Tc reduction is oxygen loss in the VHT environment due the majority of the oxygen in the vessel being displaced by Ar and to corrosion of the stainless steel vessel. Signs of corrosion are typically observed on the interior walls of the VHT vessels after testing. The oxidation state of Tc is related in a simple way to the presence of oxygen; for example:

$$
(4 \mathrm{x}+2) \mathrm{H}_{2} \mathrm{O}+4 \mathrm{NaTcO}_{4}=4 \mathrm{TcO}_{2} \bullet \mathrm{xH}_{2} \mathrm{O}+4 \mathrm{NaOH}+3 \mathrm{O}_{2}
$$

Under oxidizing conditions the above equation is driven to the left, where $\mathrm{TcO}_{2} \bullet \mathrm{xH}_{2} \mathrm{O}$ is rapidly oxidized to Tc(VII); under reducing conditions, the equation is driven to the right, where $\mathrm{NaTcO}_{4}$ is rapidly reduced to Tc(IV). Therefore, if the system becomes oxygen depleted, then $\mathrm{Tc}(\mathrm{VII})$ will be reduced to Tc(IV). In addition, further oxygen depletion in the VHT environment may be caused by oxidation of the protective $\mathrm{Cr}_{2} \mathrm{O}_{3}$ layer on the stainless steel vessel, which has been observed in corrosive environments. ${ }^{67}$ Further work is needed to test this hypothesis.

The observation that Re remains oxidized while Tc is reduced can be explained by the redox behavior of these metals in the presence of Fe, the most abundant redox-active metal in the VHT system. The Fe(II)/Fe(III) equilibrium will determine the oxygen fugacity in the VHT vessel, and therefore, the redox state of the other metals.

\section{Conclusions}

The XAS and SEM information obtained for the original Tc-containing glasses and corresponding VHT samples shows that the alteration processes that took place, significantly changed the Tc valence and distribution within each sample. XAS data show that despite having different initial Tc distributions in the two original waste glasses, all Tc was reduced to Tc(IV) as both glasses were altered under VHT conditions. Both XAS and SEM show that Tc concentrated near the surface of the VHT sample. Since there is no clear evidence from SEM or XRD of Tc-containing crystals in either VHT altered sample, amorphous Tc-silicate gel-like phases may have formed near the sample surface.

Re behaved quite differently from Tc in response to VHT alteration. Re speciation remained unchanged from the original glass to the altered samples, where most, if not all Re is perrhenate. $\mathrm{Re}_{2} \mathrm{O}_{7}$ concentrations increase from small values near the VHT sample surface to values near that for the original glass toward the sample center. This behavior indicates that some Re was lost from the outer portions of the VHT coupon, which is not consistent with Tc behavior. Re is not a good surrogate for Tc under VHT conditions, which reinforces the earlier findings concerning different Tc and Re behavior as these elements are incorporated into waste glasses. ${ }^{45}$

Differences between Tc and Re valence behavior in the VHT environment can be related to the different redox potentials for these two elements. ${ }^{45}$ Since Fe dominates the redox sensitive cation content in the glass chemistries studied, the $\mathrm{Fe}(\mathrm{III}) / \mathrm{Fe}(\mathrm{II})$ redox couple can maintain oxygen fugacity at levels where Tc(IV) and Re(VII) coexist. 
The VHT results presented are a first evaluation of Tc and Re behavior within this environment. One must consider that the VHT may not be a realistic model of what a glass may encounter over time in a waste repository; the following statements need to be considered with the above short-comings in mind. From the perspective of Tc immobilization, reduction of Tc can be regarded as desirable, since $\mathrm{Tc}(\mathrm{IV})$ is less mobile in the environment than $\mathrm{Tc}$ (VII) within pertechnetate. However, Tc was also found to migrate and concentrate toward the surface of the waste-form material as alteration takes place, which is clearly undesirable. Furthermore, it is possible that over long time periods, Tc(IV) near the surface of an altered glass in air may oxidize to form the mobile pertechnetate species. Further experiments are necessary to determine whether such trends are replicated in conditions more consistent with a long-term environment in a nuclear waste repository. 


\section{Relevance to U.S. DOE Issues}

Redox behavior of technetium and rhenium in glass waste forms

Technetium volatility during DOE waste vitrification is an important issue related to the redox behavior of technetium Reducing conditions that produce non-volatile $\mathrm{Tc}(\mathrm{IV})$ decrease the amount of Tc lost during vitrification. The results for Hanford LAW glass show that Tc is largely present as Tc(IV) if the oxygen fugacity is less than $~ 100 \mathrm{ppm}$ or if the $\mathrm{Fe}(\mathrm{II}) /$ total Fe ratio is greater than $\sim 0.25$. While these results may identify desirable redox potentials for limiting Tc volatility during waste vitrification, their actual utility for Hanford LAW needs to be further evaluated. During LAW vitrification of Hanford LAW, nitrates decompose according to the general reaction $4 \mathrm{NaNO}_{3}=-2 \mathrm{Na}_{2} \mathrm{O}+2 \mathrm{~N}_{2}+5 \mathrm{O}_{2}$. Consequently, as nitrate decomposes, the oxygen fugacity is greatly increased, thereby increasing the amount of volatile $\mathrm{Tc}$ (VII) in the glass melt. This effect is partially off-set through the addition of reductants (sugar at Hanford) to control glass melt foaming. An important question is then whether conditions can be made sufficiently reducing to control technetium volatility while not becoming so reducing as to compromise the operation of the melter through the formation of molten metal or sulfide phases.

A surprising result of this research was the behavior of rhenium, which was postulated to behave similarly to technetium but was thought to require more reducing conditions. However, under certain redox conditions, rhenium behaves quite differently than technetium. Under the conditions examined in this study, only perrhenate and rhenium metal are stable in the glass melt. In fact, under certain situations, the redox behavior of rhenium can be so different from that of technetium that rhenium is would not be useful as a surrogate for technetium if redox is important.

Behavior of rhenium and technetium during the vapor hydration test (VHT)

The VHT test provides an analog of the behavior of technetium in a waste repository. Technetium is not retained by the glass alteration products and its rate of release from the glass is determined only by the durability of the waste form. However, release of technetium to the environment is determined by the redox state of the environment into which technetium is released. In the case of the VHT test, the atmosphere was depleted in oxygen due to corrosion of the stainless steel vessel; consequently, technetium was present as immobile Tc(IV) species. On the other hand, if the VHT environment was aerobic, it is possible that technetium would be present as environmentally mobile $\mathrm{Tc}(\mathrm{VII})$. The durability of the waste form determines the rate of release into the repository, but the redox potential of the repository could determine the rate of release into the environment.

\section{Recommendations}

In view of the findings from this research program, careful consideration should be given to the future use of rhenium as a surrogate for technetium, particularly when redox behavior is important. Rhenium is perhaps the best available surrogate for technetium under certain, narrow oxidizing conditions were both rhenium and technetium are present in the +7 state. In addition, the behavior of technetium and rhenium during the VHT test was found to be quite different, where technetium migrated to the surface of the VHT samples more quickly than did rhenium. 


\section{Project Productivity}

The goals of this project were to better understand the behavior of technetium and its surrogate rhenium during vitrification and corrosion of waste glasses. As described above, this goal was achieved and previously unknown information was obtained. However, in view of the complexity of the issues investigated, further studies in this area are highly recommended.

\section{Personnel Supported}

Dr. Wayne W. Lukens, Staff Scientist

Lawrence Berkeley National Laboratory

Dr. David A. McKeown, Staff Scientist

Vitreous State Laboratory, The Catholic University of America

Dr. Isabelle S. Muller, Staff Scientist

Vitreous State Laboratory, The Catholic University of America

Dr. Ian L. Pegg, Professor, Director

Vitreous State Laboratory, The Catholic University of America

Dr. David K. Shuh, Senior Staff Scientist

Lawrence Berkeley National Laboratory

\section{Publications}

David A. McKeown, Andrew C. Buechle, Wayne W. Lukens, David K. Shuh, Ian L. Pegg, "Raman studies of technetium in borosilicate waste glass" Radiochim. Acta, 2007, 95, 275280.

Wayne W. Lukens, David A. McKeown, Andrew C. Buechele, Isabelle S. Muller, David K. Shuh, Isabelle S. Muller, Ian L. Pegg, "Dissimilar behavior of technetium and rhenium in borosilicate waste glass as determined by X-ray absorption spectroscopy," Chem. Mater. 2007, 19, 559-566.

David A. McKeown, Andrew C. Buechele, Wayne W. Lukens, David K. Shuh, Ian L. Pegg, “Tc and Re behavior in borosilicate waste glass vapor hydration tests," Environ. Sci. Technol., 2007, 41, 431-436.

Wayne W. Lukens, David K. Shuh, Isabelle S. Muller, David A. McKeown, “X-ray absorption fine structure studies of speciation of technetium in borosilicate glasses" Mat. Res. Soc. Symp. Proc. 2004, 802, 101-106. 
David A. McKeown; Andrew C. Buechele; Wayne W. Lukens; David K. Shuh;, Ian L. Pegg; "Technetium and Rhenium behavior in Borosilicate Waste Glass Vapor Hydration Tests", in Scientific Basis for Nuclear Waste Management XXX, edited by D.S. Dunn, C. Poinssot, B. Begg (Mater. Res. Soc. Symp. Proc. v. 985, Warrendale, PA, 2007), NN6.3.

\section{Interactions}

\section{Presentations}

"Behavior of technetium, rhenium, and ruthenium in glass wasteforms" W.W. Lukens, D.A. McKeown, A.C. Buechele, I.S. Mueller, D.K. Shuh, I.L. Pegg, ACS National Meeting, Boston, August 2007.

"Dissimilar behavior of technetium and its nonradioactive surrogate rhenium in waste glasses" W.W. Lukens, D.A. McKeown, A.C. Buechele, I.S. Mueller, D.K. Shuh, I.L. Pegg, Materials Research Society Meeting, Boston, November 2006.

“Technical Assessment of Bulk Vitrification Process/Product for Tank Waste Treatment at the Department of Energy Hanford Site” D. Kaback, I.L. Pegg, D.K. Shuh, and F. Woolley, U. S. Department of Energy Reference SR-311-2-511, Technical Expertise Project \#608, May 2006. [PNNL/CH2MHill site visit, Richland, WA 15-17 January 2006)].

"Behavior of technetium in highly alkaline solution and in cement and glass waste forms" W. W. Lukens, J. J. Bucher, P. G. Allen, D. K. Shuh, N. M. Edelstein. Stanford Synchrotron Radiation Laboratory Users’ Meeting, Menlo Park, CA, October 2005.

"The chemistry of technetium in nuclear waste" D. K. Shuh and W. W. Lukens, U.S. Department of Energy Basic Energy Sciences Triennial Review 2005, Stanford Synchrotron Radiation Laboratory, Stanford, CA, February 2005 (invited)

"The materials science and chemistry of nuclear waste forms explored by synchrotron radiation" D. K. Shuh, Department of Geology, Washington and Lee University, Lexington, VA, 29 September 2004.

"Evolution of technetium speciation in reducing grout” W. W. Lukens, J. J. Bucher, D. K. Shuh, N. M. Edelstein, Materials Research Society Meeting, San Francisco, CA, April 2004.

"X-ray absorption fine structure studies of speciation of technetium in borosilicate glasses" W. W. Lukens, D. K. Shuh, I. S. Muller, D. A. McKeown, Materials Research Society Meeting, Boston, MA, December 2003. 


\section{Future Work}

This report marks the end of this project. No future work is anticipated under U.S. DOE, Office of Science, Office of Biological and Environmental Research funding. 


\section{Literature Cited}

1. Lukens, W. W.; Bucher, J. J.; Shuh, D. K.; Edelstein, N. M., Evolution of technetium speciation in reducing grout. Env. Sci. Tech. 2005, 29, 8064-8070.

2. National Research Council, Research Needs for High-Level Waste Stored in Tanks and Bins at U.S. Department of Energy Sites: Environmental Management Science Program. National Academy Press: Washington, D.C., 2001.

3. Mann, F. M.; Puigh, R. J.; Rittman, P. D.; Kline, N. W.; Voogd, J. A.; Chen, Y.; Eiholzer, C. R.; Kincaid, C. T.; McGrail, B. P.; Lu, A. H.; Williamson, G. F.; Brown, N. R.; LaMont, P. E. Hanford immobilized low-activity tank waste performance assessment; DOE/RL-97-69; Department of Energy: Richland, WA, 1998.

4. Bibler, N. E.; Fellinger, T. L.; Marra, S. L.; O'Driscoll, R. J.; Ray, J. W.; Boyce, W. T. Tc-99 and Cs-137 Volatility from the DWPF Production Melter during Vitrification of the First Macrobatch at the Savannah River Site; WSRC-MS-99-00860; Westinghouse Savannah River Company: Aiken, S. C., 1999.

5. Darab, J. G.; Smith, P. A., Chemistry of technetium and rhenium species during low-level radioactive waste vitrification. Chem. Mater. 1996, 8, 1004.

6. Bechtel SAIC Company Technical basis document No. 10: unsaturated zone transport; U.S. DOE Office of Civilian Radioactive Waste Management: Las Vegas, Nevada, 2004.

7. Turcotte, M.-D. S.; King, C. M. Environmental implications of Tc-99 DWPF operation and Saltcrete; DPST-82-608; Savannah River Laboratory: Aiken, SC, 1983.

8. Seitz, R. R.; Walton, J. C.; Dicke, C. A.; Cook, J. R., Near-field performance assessment for the Saltstone disposal facility. Mat. Res. Soc. Symp. Proc. 1993, 294, 731-736.

9. $\quad$ Ebert, W. L.; Bakel, A. J.; Bowers, D. L.; Buck, E. C.; Emery, J. W. The incorporation of technetium into a representative low-activity waste glass; ANL/CMT/CP-92096; Argonne National Laboratory: Argonne, IL, 1997.

10. Lanza, F.; Cambini, M.; Della Rossa, M.; Parnisari, E., Investigation of the form in which technetium is retained in a borosilicate glass containing simulated high level nuclear waste. J. Trace and Microprobe Techniques 1992, 10, 257-265.

11. Migge, H., Thermochemical comparison of the systems Re-O and Tc-O. Mat. Res. Symp. Proc. 1989, 127, 205-213.

12. Migge, H., Simultaneous Evaporation of Cs and Tc During Vitrification - a Thermochemical Approach. Mat. Res. Soc. Symp. Proc. 1990, 176, 411.

13. Bibler, N. E.; Jurgensen, A. R., Leaching Tc-99 from SRP glass in simulated tuff and salt groundwaters. Mat. Res. Symp. Proc. 1988, 112, 585-593. 
14. Kim, D. S.; Soderquist, C. Z.; Icenhower, J. P.; McGrail, B. P.; Scheele, R. D.; McNamara, B. K.; Bagaasen, L. M.; Schweiger, M. J.; Crum, J. V.; Yeager, D. J.; Matyas, J.; Darnell, L. P.; Schaef, H. T.; Owen, A. T.; Kozelisky, A. E.; Snow, L. A.; Steele, M. J. Tc reductant chemistry and crucible melting studies with simulated Hanford low-activity waste; PNNL-15131; Pacific Northwest National Laboratory: Richland, WA, 2005.

15. Schreiber, H. D.; Hockman, A. H., Redox chemistry in candidate glasses for nuclear waste immobilization. J. Amer. Ceram. Soc. 1987, 70, 591.

16. Nechamkin, H.; Kurtz, A. N.; Hiskey, C. F., A method for the preparation of rhenium(VI) oxide. J. Am. Chem. Soc. 1951, 73, 2828-2831.

17. Meyer, R. E.; Arnold, W. D., The electrode potential of the Tc(IV)-Tc(VII) couple. Radiochimica Acta 1991, 55, 19-22.

18. Boyd, G. E.; Cobble, J. W.; Smith, W. T., Thermodynamic properties of technetium and rhenium compounds. III. Heats of formation of rhenium heptoxide and trioxide, and a revised potenital diagram for rhenium. J. Am. Chem. Soc. 1953, 75, 5783-5784.

19. Freude, E.; Lutze, W.; R"ussel, C.; Schaeffer, H. A., Investigation of the redox behavior of technetium in borosilicate glass melts by voltammetry. Mat. Res. Soc. Symp. Proc. 1989, 127, 199-204.

20. Wilson, A. D., The micro-determination of ferrous iron in silicate minerals by a volumetric and a colorimetric method. The Analyst 1960, 85, 823-827.

21. Whitehead, D.; Malik, S. A., Determination of ferrous and total iron in silicate rocks by automated colorimetry. Anal. Chem. 1975, 47, 554-556.

22. Golcar, G. R.; Colton, N. G.; Darab, J. G.; Smith, H. D. Hanford tank waste simulants specification and their applicability for the retrieval, pretreatment, and vitrification processes; BNFL-RPT-012, Rev. 0; Pacific Northwest National Laboratory: Richland, WA, 2000.

23. Matlack, K. S.; Kot, W. K.; Pegg, I. L. DM100 HLW and LAW tests of the influence of technetium on cesium volatility using rhenium as a technetium surrogate; VSL-04R7101; Vitreous State Laboratory, The Catholic University of America: Washington, DC, 2004.

24. Tröger, L.; Arvanitis, D.; Baberschke, K.; Michaelis, H.; Grimm, U.; Zschech, E., Full correction of the self-absorption in soft-fluorescence extended x-ray-absorption fine structure. Phys. Rev. B 1992, 46, 3283-3289.

25. Koningsberger, D. C.; Prins, R., X-Ray Absorption: Principles, Applications, Techniques of EXAFS, SEXAFS, and XANES. John Wiley \& Sons: New York, 1988. 
26. Newville, M., IFEFFIT: interactive XAFS analysis and FEFF fitting. J. Synchrotron Rad. 2001, 8, 322-324.

27. Ravel, B., ATHENA and ARTEMIS interactive graphical data analysis using IFEFFIT. Physica Scripta 2005, T115, 1007-1010.

28. Rehr, J. J.; Albers, R. C.; Zabinsky, S. I., High-order multiple-scattering calculations of x-ray-absorption fine structure. Phys. Rev. Lett. 1992, 69, 3397-3400.

29. Lukens, W. W.; Shuh, D. K.; Muller, I. S.; McKeown, D. A., X-ray absorption fine structure studies of speciation of technetium in borosilicate glasses. Mat. Res. Symp. Proc. 2004, 208, (2004), 101-107.

30. Webb, S. M., Sixpack: A graphical user interface for XAS analysis using IFEFFIT. Physica Scripta 2005, T115, 1001-1014.

31. Ressler, T.; Wong, J.; Roos, J.; Smith, I. L., Quantitative speciation of Mn-bearing particulats emitted from autos burning (methylcyclopentadienyl)manganese tricarbonyladded gasolines using XANES spectroscopy. Env. Sci. Tech. 2000, 34, 950-958.

32. Mooney, R. C. L., The crystal structure of element 43. Phys. Rev. 1947, 72, 1269.

33. Agte, C.; Alterthum, H.; Becker, K.; Heyne, G.; Moers, K., Z. Anorg. Allg. Chem. 1931, 196, 129-159.

34. McKale, A. G.; Veal, B. W.; Paulikas, A. P.; Chan, S.-K., Generalized RamsaurTownsend effect in extended x-ray-absorption fine structure. Phys. Rev. B 1988, 38, 10919-10921.

35. Mylswamy, S.; Wang, C. Y.; Liu, R. S.; Lee, J.-F.; Tang, M.-J.; Lee, J.-J.; Weng, B.-J., Anode catalysts for enhanced methanol oxidation: an in situ XANES study of PtRu/C and PtMo/C catalysts. Chem. Phys. Lett. 2005, 412, 444-448.

36. Min, M.; Cho, J.; Cho, K.; Kim, H., Particle size and alloying effects of Pt-based alloy catalysts for fuel cell applications. Electrochimica Acta 2000, 45, 4211-4217.

37. Magneli, A., Studies on rhenium oxides. Acta Chem. Scand. 1957, 11, 28-33.

38. Hermann, C.; Lohrmann, O.; Philipp, H., Struckturbericht, Band II. Akademische Verlagsgesellschaft M. B. H.: Leipzig, 1937.

39. Medlin, M. W.; Sienerth, K. D.; Schreiber, H. D., Electrochemical determination of reduction potentials in glass-forming melts. J. Non-Cryst. Sol. 1998, 240, 193-201.

40. Schreiber, H. D.; Balazs, G. B.; Carpenter, B. E.; Kirkley, J. E.; Minnix, L. M.; Jamison, P. L., An Electromotive Force Series in a Borosilicate Glass-Forming Melt. Commun. Amer. Ceram. Soc. 1984, C-106. 
41. Russel, C., The electrochemical behavior of some polyvalent elements in a soda-limesilica glass melt. J. Non-Cryst. Sol. 1990, 119, 303-309.

42. Russel, C., Redox reactions during cooling of glass melts - a theoretical consideration. Glastech. Ber. 1989, 62, 199-203.

43. Shomate, C. H., A method for evaluating and correlating thermodynamic data. J. Phys. Chem. 1954, 58, 368-372.

44. Lukens, W. W.; Bucher, J. J.; Edelstein, N. M.; Shuh, D. K., Products of pertechnetate radiolysis in highly alkaline solution: structure of $\mathrm{TcO}_{2} \cdot \mathrm{xH}_{2} \mathrm{O}$. Env. Sci. Tech. 2002, 36, 1124-1129.

45. Lukens, W. W.; McKeown, D. A.; Buechele, A. C.; Muller, I. S.; Shuh, D. K.; Pegg, I. L., Dissimilar behavior of technetium and rhenium in borosilicate waste glass as determined by X-ray absorption spectroscopy. Chem. Mater. 2007, 19, (3), 559-566.

46. Sarsfield, M. J.; Sutton, A. D.; Livens, F. R.; May, I.; Taylor, R. J., Raman spectroscopy of silver pertechnetate. Acta Cryst. 2003, C59, I45-I46.

47. Eysel, H. H.; Kanellakopulos, B., Raman-spectra, absolute Raman intensities and electrooptical parameters of pertechnetate, perrhenate and periodate ions in aqueoussolution. J. Raman Spect. 1993, 24, (2), 119-122.

48. McKeown, D. A.; Muller, I. S.; Gan, H.; Pegg, I. L.; Kendziora, C. A., Raman studies of sulfur in borosilicate waste glasses: sulfate environments. J. Non-Cryst. Sol. 2001, 288, (1-3), 191-199.

49. McKeown, D. A.; Muller, I. S.; Buechele, A. C.; Pegg, I. L.; Kendziora, C. A., Structural characterization of-high-zirconia borosilicate glasses using Raman spectroscopy. J. NonCryst. Sol. 2000, 262, (1-3), 126-134.

50. Goncharov, A. F.; Struzhkin, V. V., Raman spectroscopy of metals, high-temperature superconductors and related materials under high pressure. J. Raman Spect. 2003, 34, (78), 532-548.

51. Yoshihara, K., Technetium in the environment. Topics Curr. Chem. 1996, 176, 18-34.

52. Lieser, K.; Bauscher, C., Technetium in the hydrosphere and geosphere 1. Chemistry of technetium and iron in natural waters and influence of redox potential on the sorption of technetium. Radiochim. Acta 1987, 42, (205-213).

53. Ewing, R., Natural glasses: analogues of nuclear wate forms. In Scientific Basis for Nuclear Waste Management, Plenum New York, 1979; Vol. 1, pp 57-68.

54. Buechele, A. C.; Lofaj, F.; Lai, S.-T.; Pegg, I. L., Alteration phases on high sodium waste glasses after short- and long-term hydration. Ceram. Trans. 2000, 107, 251-259. 
55. Lu, X.; Perez-Cardenas, F.; Gan, H.; Buechele, A. C.; Pegg, I. L., Kinetics of alteration in vapor phase hydration tests of high sodium glass. Ceram. Trans. 2002, 132, 311-322.

56. Buechele, A. C.; Lofaj, F.; Mooers, C.; Pegg, I. L., Analysis of layer structures formed during vapor hydration testing on high sodium waste glasses. Ceram. Trans. 2002, 132, 301-209.

57. Schatz, T.; Buechele, A. C.; Mooers, C.; Wysoczanki, R.; Pegg, I. L., Vapor phase hydration of glasses in $\mathrm{H}_{2} \mathrm{O}$ and $\mathrm{D}_{2} \mathrm{O}$. Ceram. Trans. 2003, 143, 253-261.

58. Buechele, A. C.; Lofaj, F.; Muller, I. S.; Mooers, C.; Pegg, I. L., Composition effects on the vapor hydration of waste glasses. Ceram. Trans. 2004, 155, 289-296.

59. Almahamid, I.; Bryan, J.; Bucher, J. J.; Burrell, A.; Edelstein, N. M.; Hudon, E.; Kaltsoyannis, N.; Lukens, W. W.; Shuh, D. K.; Nitsche, H.; Reich, T., Electronic and structural investigations of technetium compounds by x-ray absorption spectroscopy. Inorg. Chem. 1995, 34, 193-198.

60. Allen, P. G.; Siemering, G. S.; Shuh, D. K.; Bucher, J. J.; Edelstein, N. M.; Langton, C. A.; Clark, S. B.; Reich, T.; Denecke, M. A., Technetium speciation in cement waste forms determined by x-ray absorption fine structure spectroscopy. Radiochim. Acta 1997, 76, 77-86.

61. Sayers, D. E.; Bunker, B., In X-ray Absorption: Principles, Applications, and Techniques of EXAFS, SEXAFS and XANES, Kroningsberger, D.; Prins, R., Eds. Wiley: New York, $1988 ; \mathrm{p} 211$.

62. Zabinsky, S. I.; Rehr, J. J.; Ankudinov, A.; Albers, R. C.; Eller, M. J., Multiple scattering calculations of x-ray absorption spectra. Phys. Rev. B 1995, 52, 2995-3009.

63. Muller, O.; White, W. B.; Roy, R., Crystal chemistry of some technetium-containing oxides. J. Inorg. Nucl. Chem. 1964, 26, $2075-2086$.

64. Alberto, R.; Anderegg, G.; Albinati, A., Synthesis and x-ray structure of a new Tc(IV) oxalato complex: $\mathrm{K} 4[(\mathrm{C} 2 \mathrm{O} 4) 2 \mathrm{Tc}(\mathrm{m}-\mathrm{O}) 2 \mathrm{Tc}(\mathrm{C} 2 \mathrm{O} 4) 2] \cdot 3 \mathrm{H} 2 \mathrm{O}$. Inorg. Chim. Acta 1990, $178,125$.

65. Ebert, W. L.; Wolf, S. F.; Bates, J. K., The release of technetium from defense waste processing facility glasses. Mat. Res. Symp. Proc. 1996, 412, 221-227.

66. Kunze, S.; Neck, V.; Gompper, K.; Fanghanel, T., Studies of the immobilization of technetium under near field conditions. Radiochim. Acta 1996, 74, (159-163).

67. Kritzer, P., Corrosion in high-temperature and supercritical water and aqueous solutions. J. Supercrit. Fluids 2004, 29, 1-29. 